\title{
SEX, MIGRATION AND AGING: \\ DEMOGRAPHIC OVERVIEW OF A DYNAMIC LABOUR MARKET
}

\author{
Robert Didham \\ Statistics New Zealand and Waikato University
}

\begin{abstract}
This paper provides a broad overview of some of the demographic features of the work force in the context of the population as a whole. In this respect it differs from other papers in that it provides a background picture against which topics discussed elsewhere can be measured. The purpose is to provide context for discussion and a background to contextualise labour market research. The three key themes of sex, migration and change to identify the connection between the population and the policy drivers that impinge on the labour market.
\end{abstract}

\section{Introduction}

This paper provides a broad overview of some of the demographic features of the work force in the context of the population as a whole. In this respect it differs from other papers in that it provides a background picture against which topics discussed elsewhere can be measured. The purpose is to provide context for discussion and a background to contextualise labour market research. The three key themes of sex, migration and change to identify the connection between the population and the policy drivers that impinge on the labour market. Sex is important in any dimension because of the centrality of gender relations, equity and equality. Similarly, age is fundamental both from the perspective that many of the labour market processes differ on both by age and by cohort, with differing cohort experiences and expectations. The ageing of the population is a topical component of population change. Another important element is the relationship between migration and the labour market because of the capacity of migration to ameliorate skill shortages, and the role migration plays in strengthening the ethnic, cultural and transnational relations within the market.

Recent decades have been a period of very rapid and fundamental change in the population. A broad picture of the nature and rapidity of change can be illustrated using a comparison of the adult population in 1991 with that of 2013. A convenient method of showing this graphically is to use age sex pyramids - first because these are very familiar to people and secondly a great deal of information can be shown at a glance. As is traditional the pyramids in this paper have males on the left of the axis, females on the right, with data shown by single year of age. Single year of age data is used because, unlike the commonly used 5-year age group pyramids, these provide the detail necessary to understand changes in transition ages, and to show the degree to which neighbouring birth cohorts vary in size and sex composition.

\section{A look a little back way into history}


The 1991 age-sex pyramid (figure 1) shows the shape and size of the adult usually resident population enumerated by the 1991 Census of Population and Dwellings. To provide an historical context, we can think of the 19-year-olds in 1991 as born around 1972. Those aged 29 years were born in 1962, and those in the 45-54 year age group were born during World War and include the large cohort born in 1941. This age-sex pyramid distinguishes the full-time (FT) and part-time (PT) work force, the unemployed (U/emp) who make up the remainder of the labour force, and the nonlabour force (NLF). The significant differences between male and female employment are well illustrated here. Fewer women, both numerically and proportionally, than men were employed at all ages. Moreover, the full-time and part-time work forces were even more highly gendered, with men more likely to be unemployed and women more likely to be in part-time work. This primarily related to eligibility for unemployment benefits. Women were more likely to be outside the labour force while they were rearing children, and if not working were less likely to be actively seeking work.

Figure 1: Age-sex pyramid by labour force status, New Zealand census usually resident population aged 15 years and over, 1991 Census.

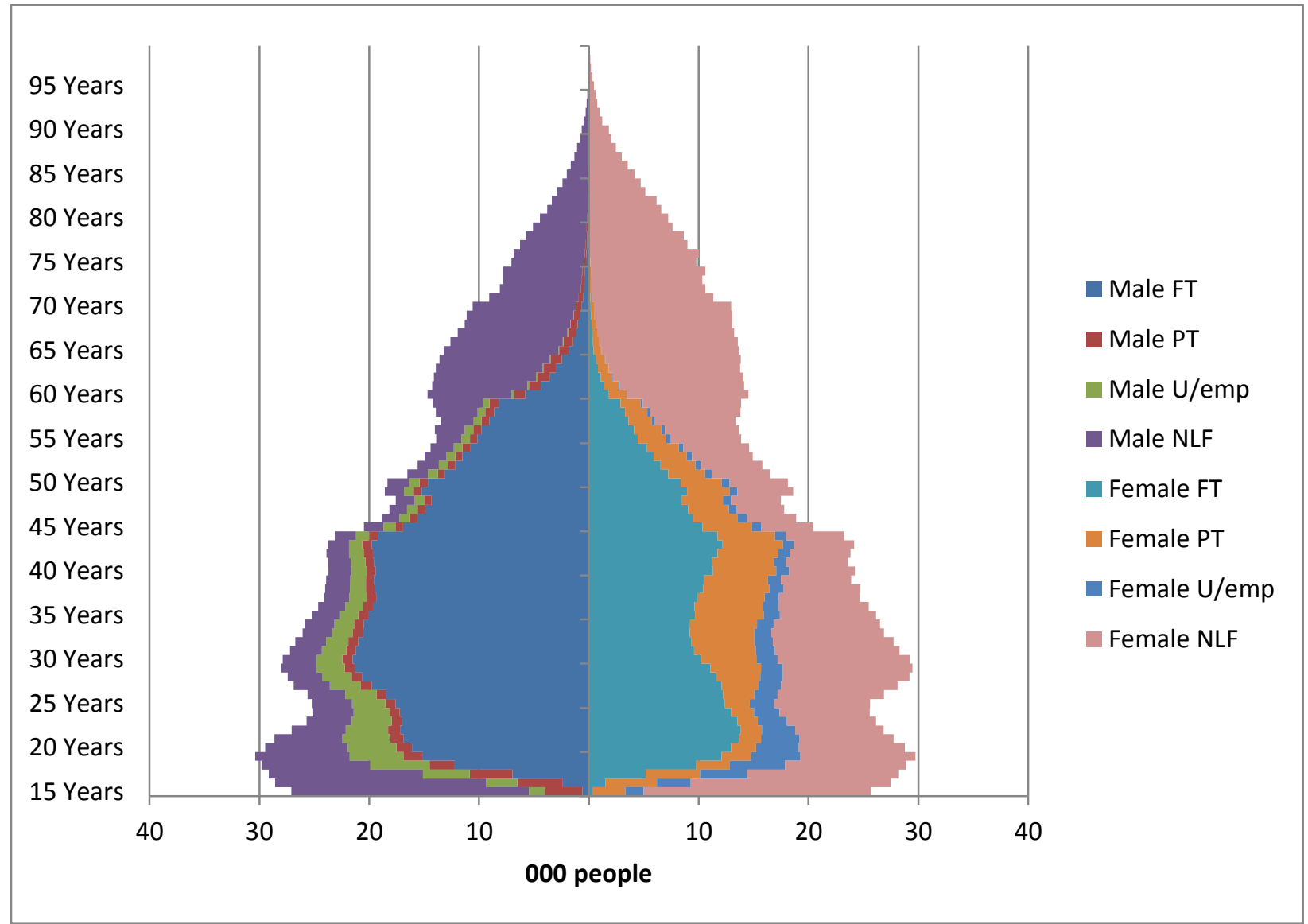

In 1991 the rapid onset of retirement around the age of 60 years was still a feature of the population. Eligibility to universal superannuation began at the age of 60 years, with very strong pressure in many occupations and from many employers for people to not continue working beyond that age. The consequences of this is seen in the pyramid with the sharp decrease in employment at 60 years of age for both sexes. Nevertheless, already there was a significant number of men and some women who continued to work beyond that age. Predominantly those still 
working were either in agriculture or were running their own businesses, but the older work force remained diverse.

Uptake of employment by youth under 25 years of age was also gendered, with males beginning work a little later than females; but males were more likely to take up full-time work immediately upon entry into employment. In contrast, women were less likely to be employed and much less likely to be in full-time work. Key determinants in the age at which people started working were full time study for both men and women, and, for women, motherhood. Young men more likely to be unemployed than to be working part-time - women had the reverse pattern but that relates to eligibility differences for women, some early childbearing and the relationship between work and family.

\section{What changed in the following 22 years?}

If we compare the 1991 pyramid (figure 1) with 2013 pyramid (figure 2), we notice instantly that the population has taken on quite a different shape.

The two pyramids are on the same scale, with the same labour force distinctions, so are directly comparable if we are looking at age effects. We can see the effect of migration on the relative size of the adult cohorts and the changes in the older cohorts as people tended to live longer. At all ages, some people have moved overseas, some have returned, and new migrants have arrived and stayed in New Zealand in the intervening years. People who were counted in both censuses have also moved "up" the pyramid because they are now 22 years older than they were in 1991. Most of those in the oldest ages in 1991 will have died. At the youngest end, those under 22 years of age had not been born in 1991, while all of those under 37 years of age were too young to have been part of the 1991 pyramid which only covers the population aged 15 years and over.

Apart from the growth in the population and the significant change of shape, the biggest single change from the workforce perspective is that by 2013 the age of 65 years had become the minimum age of entitlement for New Zealand Superannuation for most people, provided that residence requirements were met. This age was, however, no longer a valid "retirement age" because legislation to prevent age-discrimination has enabled people to continue working if they desire. Nevertheless, at that age, male workers did begin dropping out of the workforce with noticeable declines in the number employed in the 65-67 year ages. In contrast, we do not see the same rapid rate of drop-off among females. It should be noted that the male work force in the older ages remains quite large and does extend to quite advanced ages, though the occupational distributions are quite different. We return to this difference when we consider occupations of the older age groups below. 
Figure 2: Age-sex pyramid by labour force status, New Zealand census usually resident population aged 15 years and over, 2013 Census.

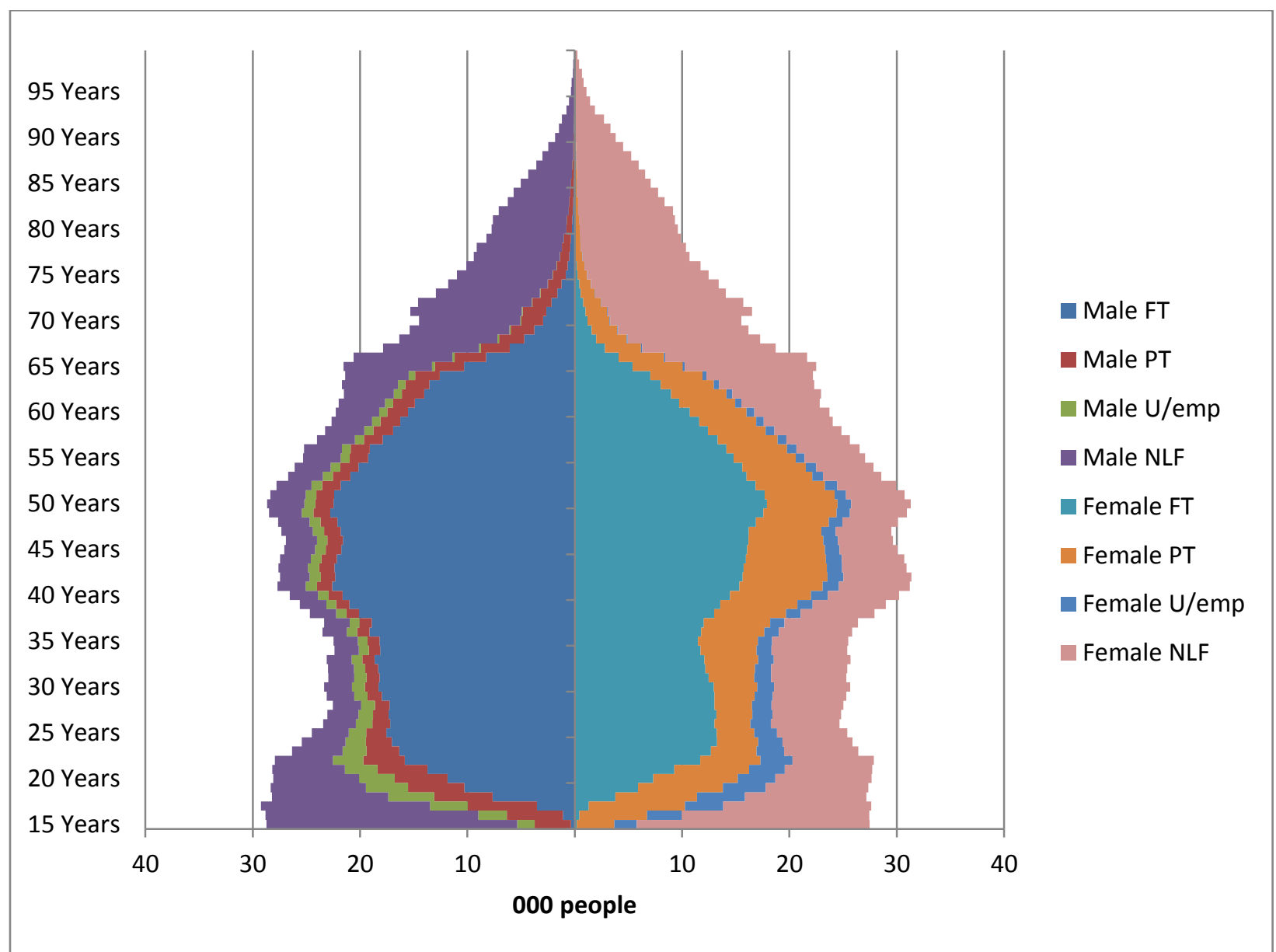

\section{Entry into the work force}

Among the young entrants into the work force, we continue to see the pattern we saw in 1991. This varies by sex, with males entering work slightly later but they do so faster and with much less parttime work than females. While this implies some under-employment among females, women likely to be either working mothers, or to be studying and working part-time. This is borne out by the high levels of study participation, relatively low levels of unemployment and the relative sizes of the non-labour force (students, parents and NEETs).

\section{Main working ages}

One obvious question that arises when we consider the change in the populations and, in particular, the dramatic change in the relative shape and size of the female work force in the main working ages when compared with the male workforce that took place in the 22 years between 1991 and 2013 is: "is it driven by gendered migration?" One possible way of illustrating this is to position the pyramids on the same scale side by side, but to offset them so that birth cohorts are horizontally adjacent (figure 3). Because the interest here has shifted to whether people are New Zealand born 
(NZB) or overseas born (OSB), for clarity the distinction is between people in the workforce (WF) or not (nWF).

Figure 3 shows the 1991 and 2013 pyramids alongside each other and positions them so that birth cohorts are adjacent to enable some measure of direct visual comparison. This means, for example that those aged 60 years in 1991 are aged 82 years by 2013, and the 15 year olds in 1991 are already approaching mid-career, aged 37 years. We can see that there is significant change due to migration in that the size of the overseas born populations have increased at all ages for both men and women. However, from the labour market perspective, importantly, the increases in the overseas born are either predominantly among the employed or, if in the non-labour force, are in the age groups most likely to be studying.

Figure 3: Age-sex pyramids, by birthplace and workforce status, New Zealand census usually resident population aged 15 years and over, 1991 and 2013 Censuses.

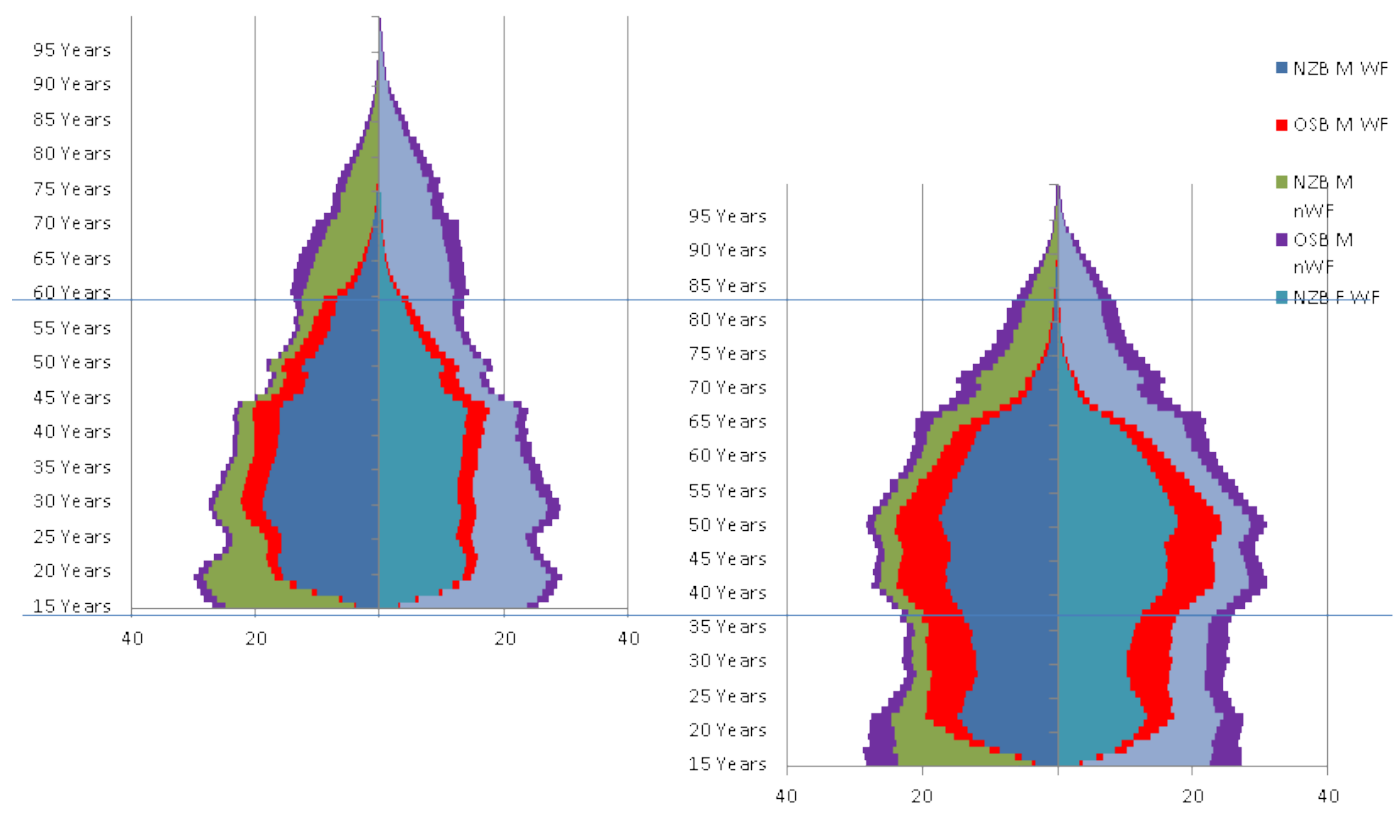

People who have returned or migrated from overseas are only part of the picture however. Outmigration too is an important part of demographic dynamics. Some people present in 1991 will have moved overseas, while some of the NZ born will be those who have returned since 1991 and not be included in the 1991 data. This exchange of people affects age groups differently. For example, people travelling in their 20s may either leave permanently or return later in life, say in their 30s/40s. Outflows also affect the overseas born with, for example, international students returning home or immigrants re-locating overseas in another country. The latter are an important part of trans-Tasman flows. The pyramids therefore demonstrate visually the ways in which the components of the population have changed over time, but do not show the extent to which the people making up these components are the same at both points in time. In other words, the pyramids demonstrate very well net changes rather than flows. 
Changes to childbearing patterns contribute to changes in the age structure of the female nonlabour force. The trend is generally towards older childbearing but there is some indication of women who have a child in their early adult years taking a break and then later having further children. These factors affect the relationship between the labour market and the non-labour market; and the effects vary with ethnicities and birthplace of the mothers.

Partially, the change in labour market structure is a consequence of changing social expectations and economic conditions. Both of these forces contribute to people staying in employment either by choice or necessity. However, the largest structural change is a consequence of population ageing. For example, in 1991 the 15-39 age groups were much bigger than 45-64 age groups. With larger birth cohorts, changes in fertility and migration in the period after World War 2, by 2013 these two broad age groups were similar in size. Moreover, because of changes in migration and to a small extent changes in mortality, the older ages in 2013 did not show the losses due to war and epidemic that we can see so clearly in 1991. One lesson from this is that population ageing is not all about the so-called baby-boomers, whether we include the whole baby boom (1937-1972) or only the portion of the marriage boom (1947-1962), because many of the additional people come from societies that did not experience baby booms (including Māori), or had baby booms with quite different histories, and many of those who could be considered "baby boomers" in New Zealand have either died or left the country.

\section{Workforce and non-workforce}

Labour market related age-sex pyramids are often shown with the work force contrasted with the total population, starting at age 15 years, as with the pyramids above. However, as soon as we need to discuss the relationship between the work force and the whole population we need to include those under 15 years of age. For reference, figure 4 is the age-sex pyramid of the adult 2013 usually resident census population.

The usually resident population has more women than men in all ages from 23 years upwards, and this can be seen clearly in the pyramid of the adult population (figure 4), with the 15-22 year old males outnumbering females, but thenceforth female outnumbering males. At least part of the sex imbalance is due to more men than women known to be missing from census, but we also have shown above that some is due to gendered migration. Some too is due to differential mortality men die younger than women, on average.

Figure 4: Age-sex pyramids, New Zealand census usually resident population aged 15 years and over, 2013 Censuses. 


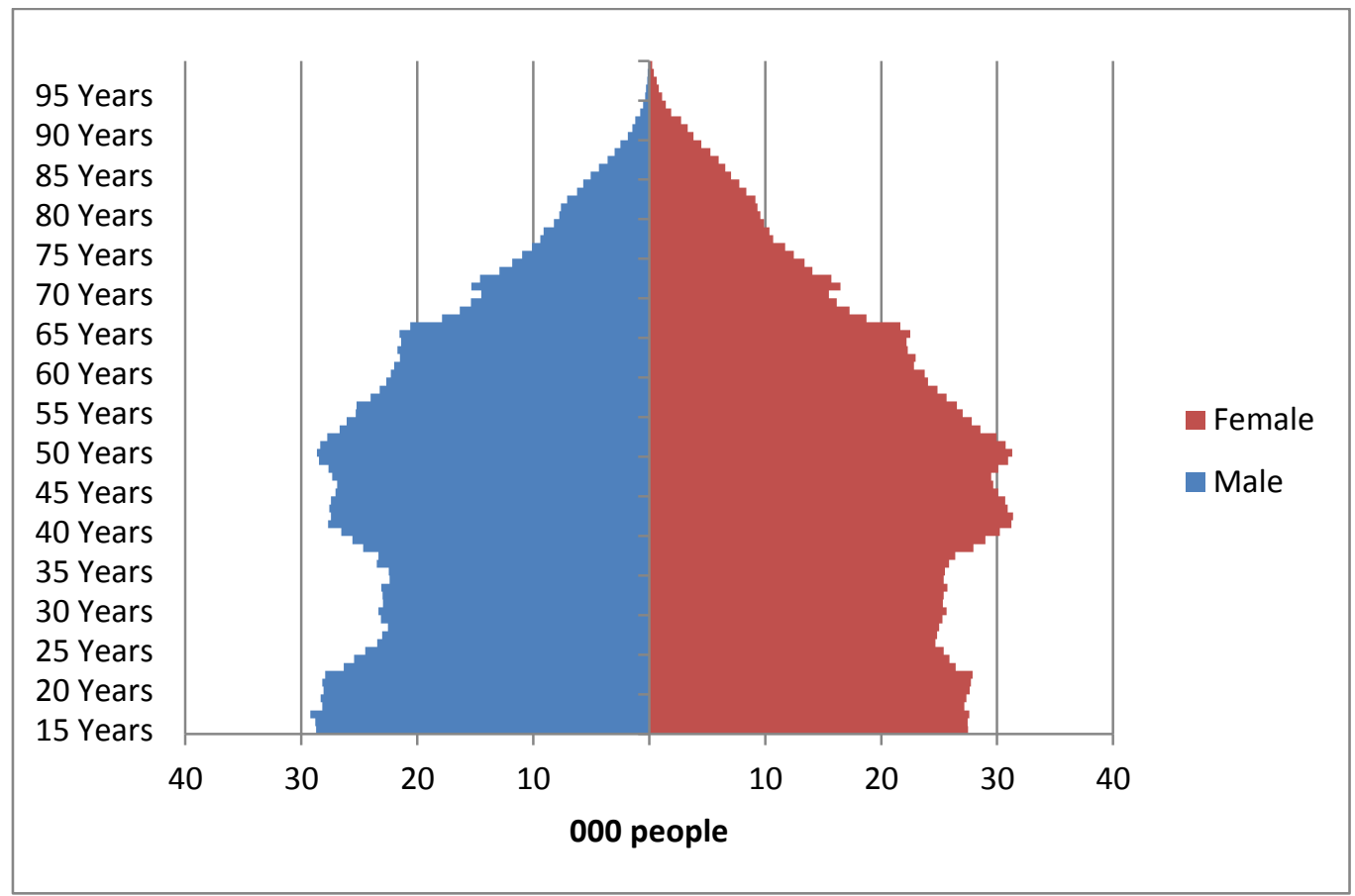

Figure 5 shows only the workforce, with full-time (FT) and part-time (PT) employed distinguished. We see that the work force grows rapidly between the ages of 15 and 23, the same age group for which males exceed females, but the rate at which male work force participation changes differs from the female rate. We see too that the work force for both males and females extends into the age groups older than 65 years.

Figure 5: Age-sex pyramid, work force, New Zealand census usually resident population, 2013 Censuses.

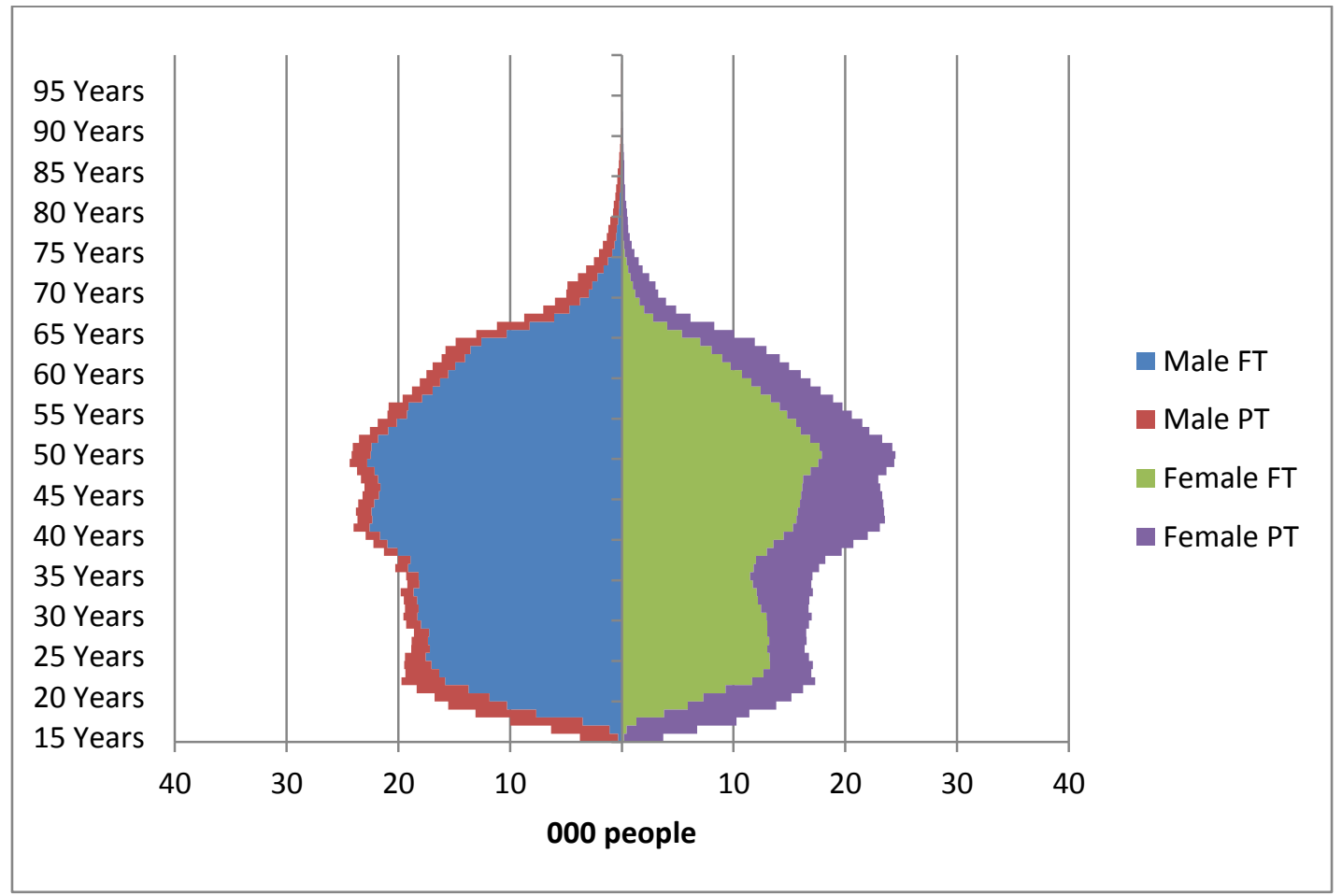


Although figure 4 and 5 do provide a quick comparison, they are missing an important part of the population: the children. If we want to contextualise the work force within the population as a whole, we might contrast the work force (figure 5) with the non-work force, including the children as shown in figure 6.

Figure 6: Age-sex pyramid, non-work force, New Zealand census usually resident population, 2013 Censuses.

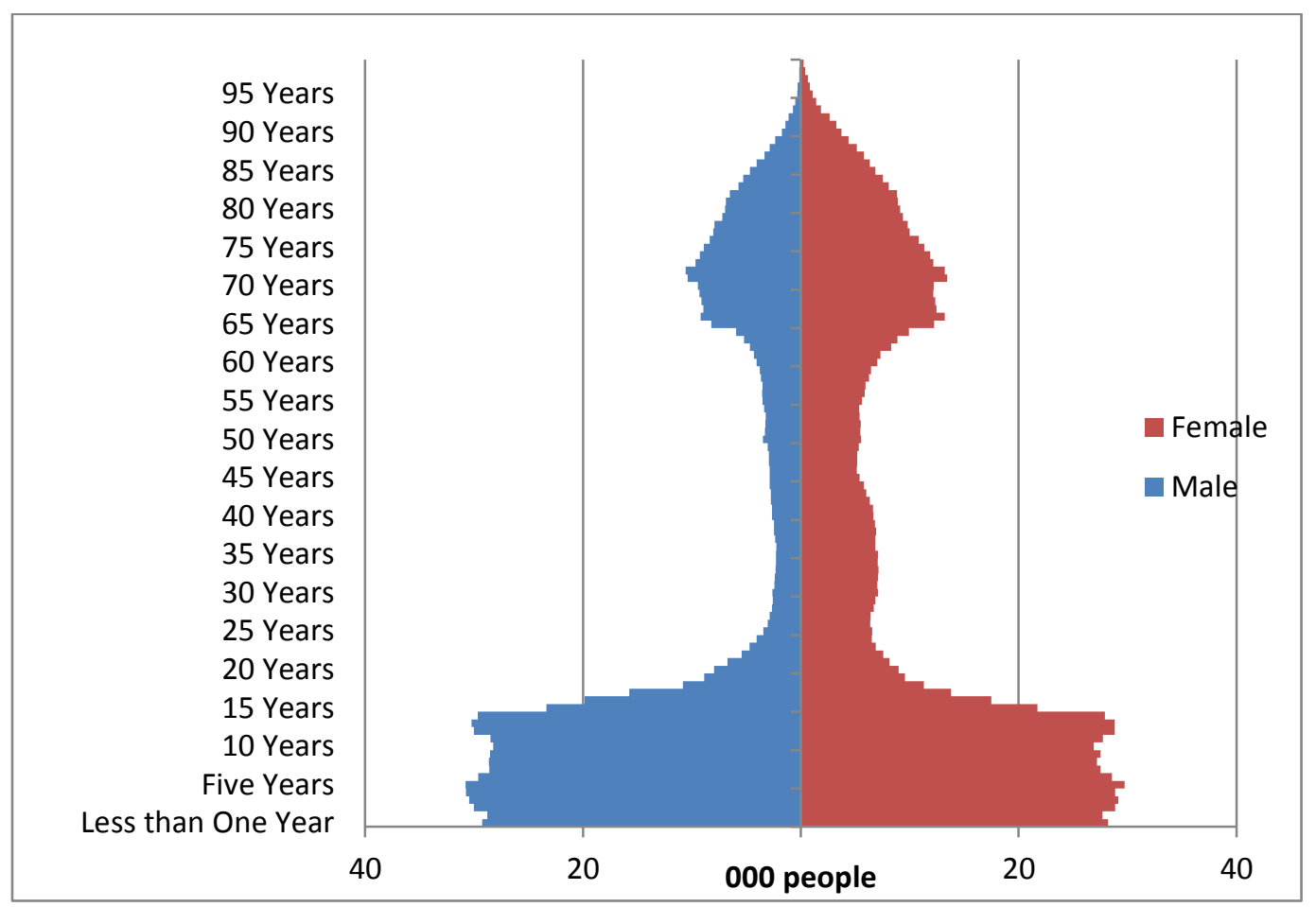

What becomes immediately apparent in the context of the population ageing debates is that children are more numerous at each age than older ages. Although children span 15 years, whereas the older ages span in excess of 30 years, there are more than three times as many children in each ages than there is in any single age among the older population. Moreover, these children are the soon to be in the work force, or to become parents and emigrants. What will become important is the large cohorts currently moving through their 40s, should they enter the older ages and not still be working. The comparison between 1991 and 2013 above suggests that we do not yet have enough information to evaluate fully whether these trends will persist, decline, or accelerate.

A key component of the population is the people in the middle adult ages who are not in the work force. These include people who are unemployed as well as people involved in child rearing, unpaid voluntary service and the independently wealthy - it is quite incorrect therefore to dismiss these as "dependent" or non-productive. More women than men are not in the work force at all ages. Women are also more likely to be working part-time (as shown in figure 4), especially during child-rearing ages. Despite equality in parental leave and care provision, women provide the bulk of these roles. This disparity extends into the older ages as well. Whereas there is a sharp transition into the work force around the ages 15-20 years for both males and females, there is not a comparable transition out of the work force at the age of 65 years. In 2013, as noted above, it can 
be seen that the employed population is already a significant feature of those aged 65 years and over.

\section{Work force and ethnicity}

In New Zealand, as in many other countries, there is intense interest in the diversity within the work force. Diversity implicates a large number of dimensions, including language, religion, age, gender and ethnicity. Some of these dimensions have been discussed elsewhere. In this section a brief overview of age, sex and work force status is illustrated with the very broad brush of level 1 of the classification of ethnicity.

While most the discussion here will focus on the smaller groupings of ethnicities, figure 7 shows the work force distribution of people of European ethnicities, the largest level 1 grouping, against which people in other groupings may be compared. Figures 7, 8 and 9 compare and contrast the age-sex pyramids of people of Māori ethnicity, Pacific ethnicities and European ethnicities. None of these populations is discrete or independent of each other, since, for example, half of the people of Māori ethnicity are also European and/or Pacific ethnicities and are included in each of the relevant groupings of ethnicities.

Figure 7: Age-sex pyramid, work force, people of European ethnicities, New Zealand census usually resident population, 2013 Censuses.

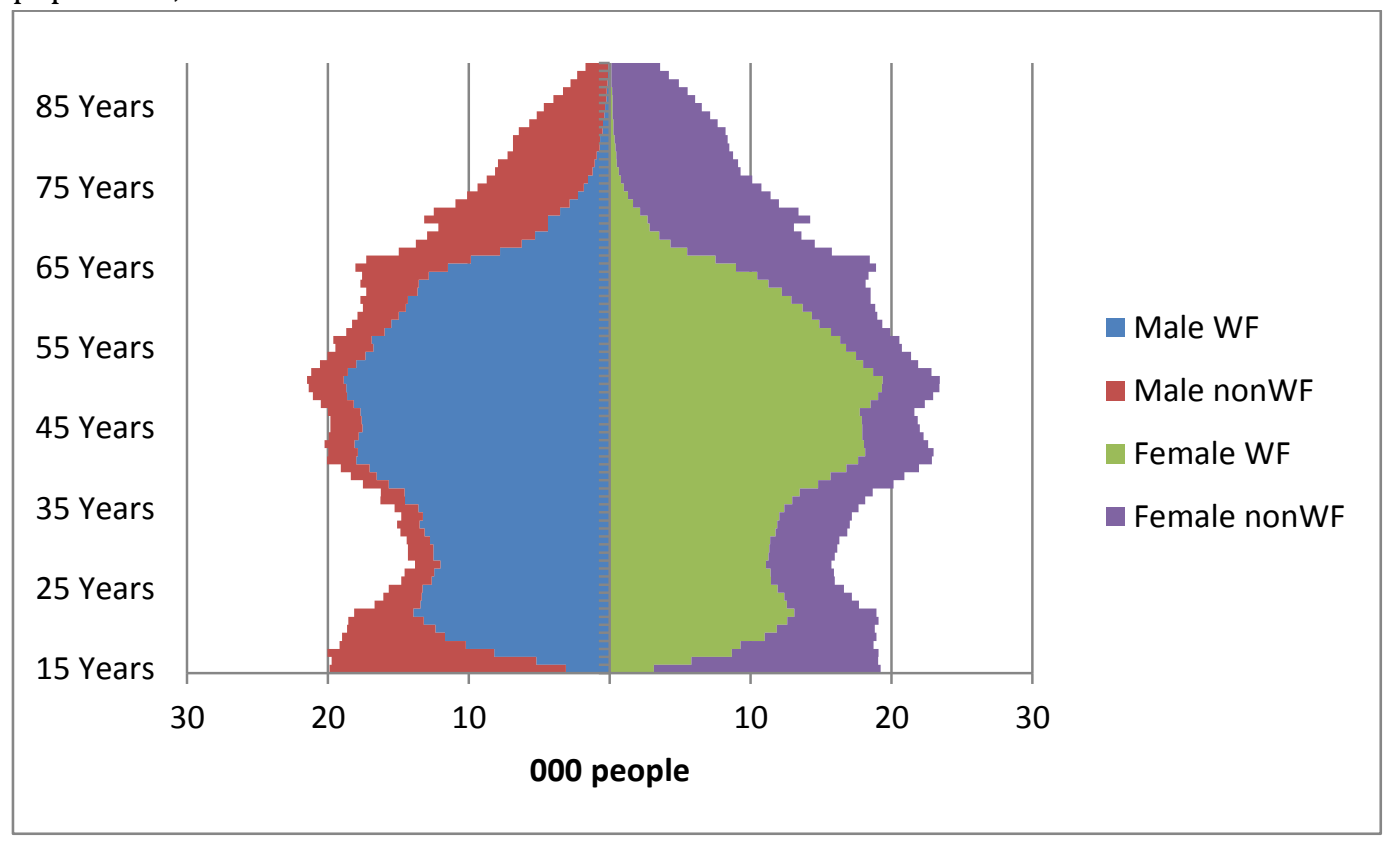

The immediately obvious feature is that the European population has a quite different shape from either Māori or Pacific, but Māori (figure 8) and Pacific (figure 9) are mutually very similar. Despite the apparent similarity of shape the Māori population is approximately twice the size of the Pacific population in New Zealand. While both the Māori and Pacific populations have broadly similar agesex profiles, though the Pacific population is younger. 
Figure 8: Age-sex pyramid, work force, people of Māori ethnicity, New Zealand census usually resident population, 2013 Censuses.

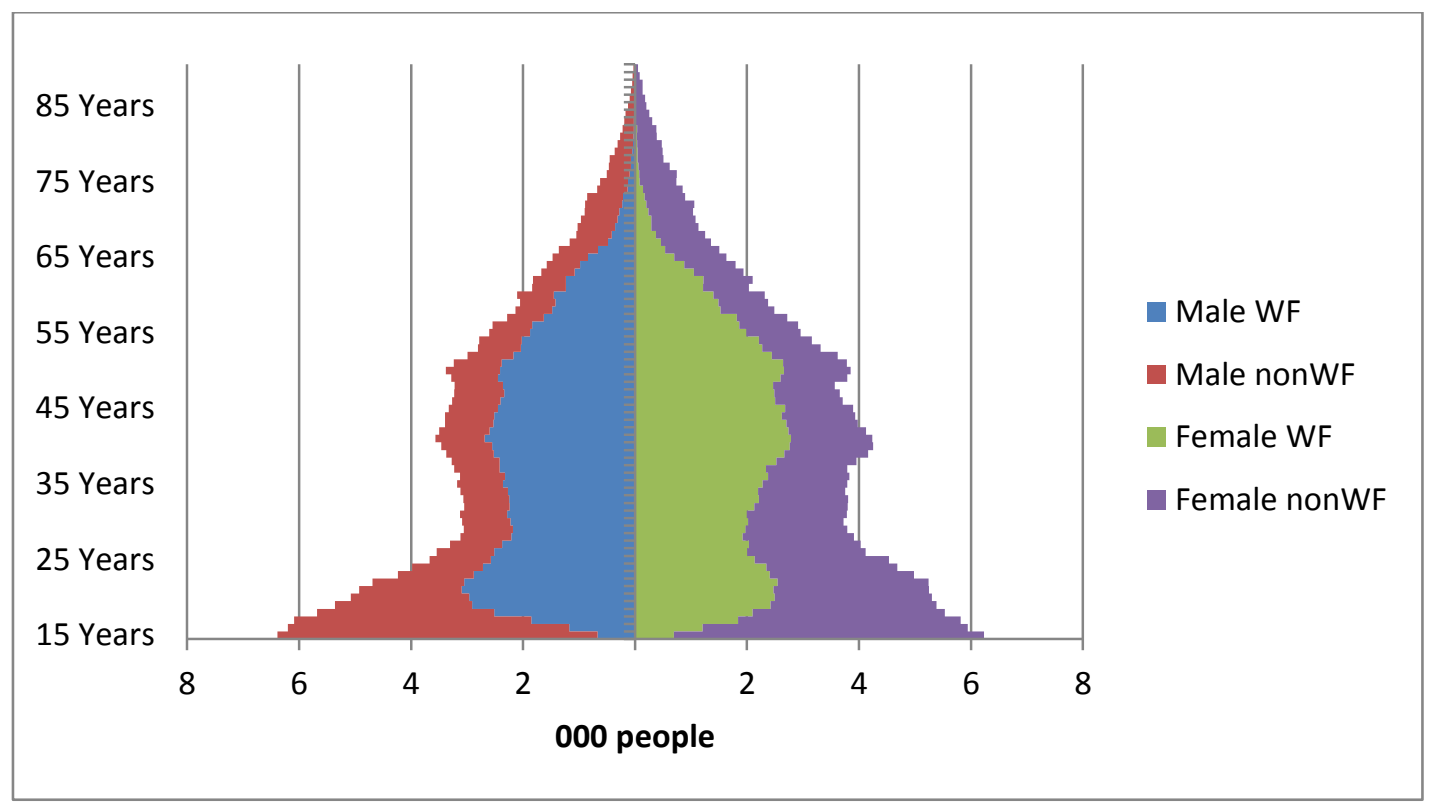

Much of the literature still discusses the people of Pacific ethnicities in the context of immigration, and it is a partially valid approach for the older ages. However, for the group as a whole, it is no longer possible to regard the Pacific population as migrants. Overall more than 60 percent of the people of Pacific ethnicities living in New Zealand were born in this country. This locally born proportion is growing rapidly, varying from less than a quarter among the older ages, to 72 percent for those in their early 20s, and well over 80 percent of Pacific children being New Zealand born. These proportions also vary significantly by geographic area, which affects the composition of work forces in regional labour markets.

Figure 9: Age-sex pyramid, work force, people of Pacific ethnicities, New Zealand census usually resident population, 2013 Censuses.

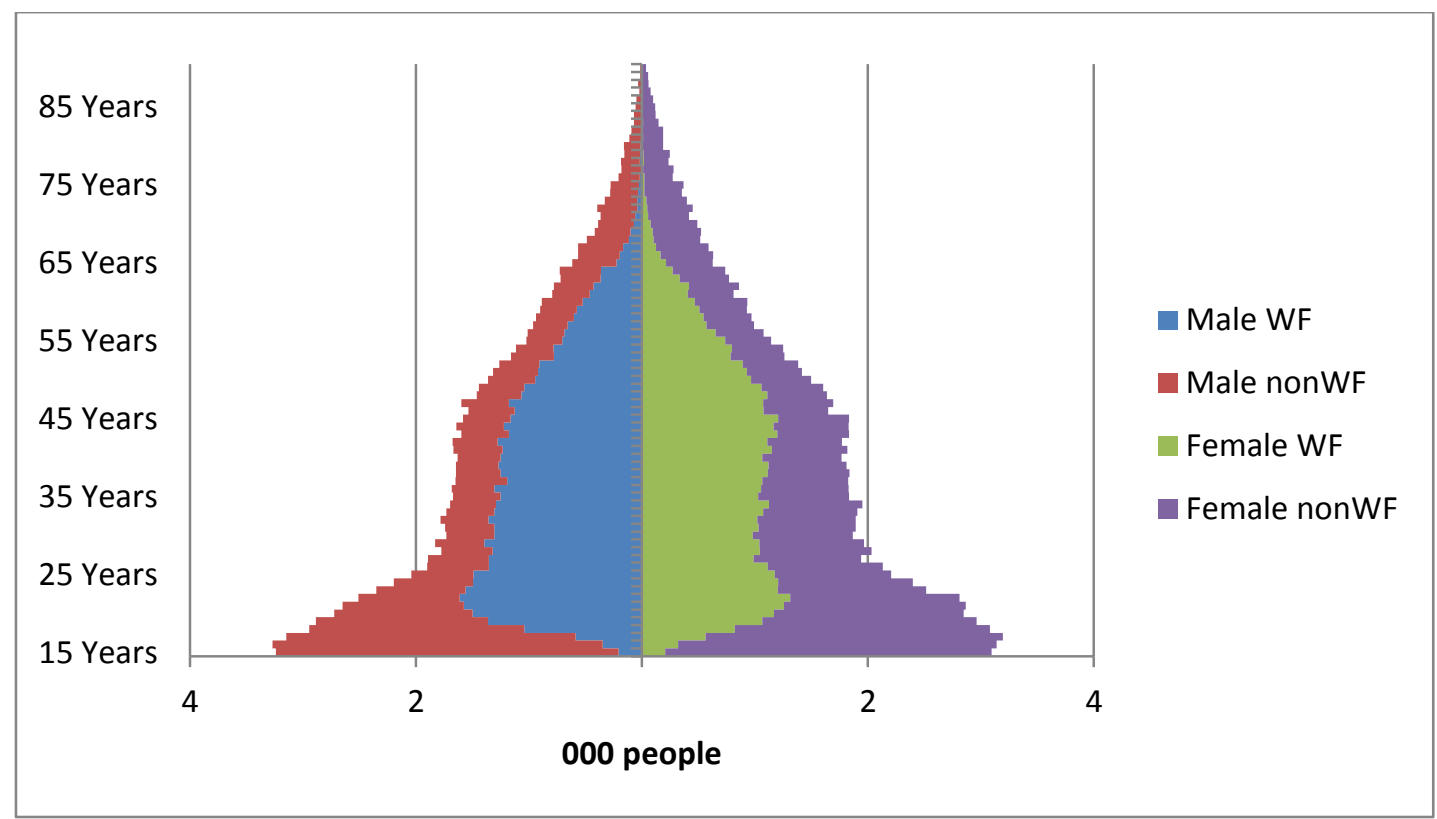


For both Māori and Pacific, the younger age profile reflects younger child-bearing patterns and this contributes to a higher proportion of the younger female population being not in the work force. In both cases, males are prominent in the non-work force, especially young males. We also see interesting differences when these are looked at sub-nationally (e.g. urban/rural) and by New Zealand Deprivation Index decile areas. That shows up significant differences between Māori and Pacific.

Mention should be made here, with respect to the Pacific population, that the pyramids include only people who are usually resident in New Zealand. The work force has two sets of porous boundaries which affect different geographic areas, and different sectors of the population, in different ways. Areas with extensive horticultural industries employ a number of Pacific workers under the Registered Seasonal Employers (RSE) scheme, which is the subject of another paper in this same session. RSE workers are generally not in these data because they are not usually resident in New Zealand for 12 months or more, unless they are returnees. The other porous boundary in labour market demography implicates people resident overseas but working in New Zealand as well as international fly-in-fly-out workers (FIFO) who may be living in New Zealand but working overseas, most commonly in highly specialised occupations or in the resources sector.

In contrast with Māori and Pacific, people of Asian ethnicities and people in the grouping of ethnicities referred to as MELAA (an acronym for Middle Eastern, Latin American and African) represent populations dominated by new migrants. While some communities, for example, Chinese, Indian and Syrian, have been a significant part of New Zealand history for much longer than a century, there has been rapid growth in both numbers and diversity in the last two decades with changes in principal migration source countries, New Zealand's partial compliance with refugee quota agreements and the growth of locally born populations. In this respect, the growth of the Asian population mirrors the slightly earlier history of migration from the Pacific from the 1970s and 1980s. As with Māori and Pacific, Asian and MELAA populations have mutually similar age-sex profiles.

Figure 10: Age-sex pyramid, work force, people of Asian ethnicities, New Zealand census usually resident population, 2013 Censuses. 


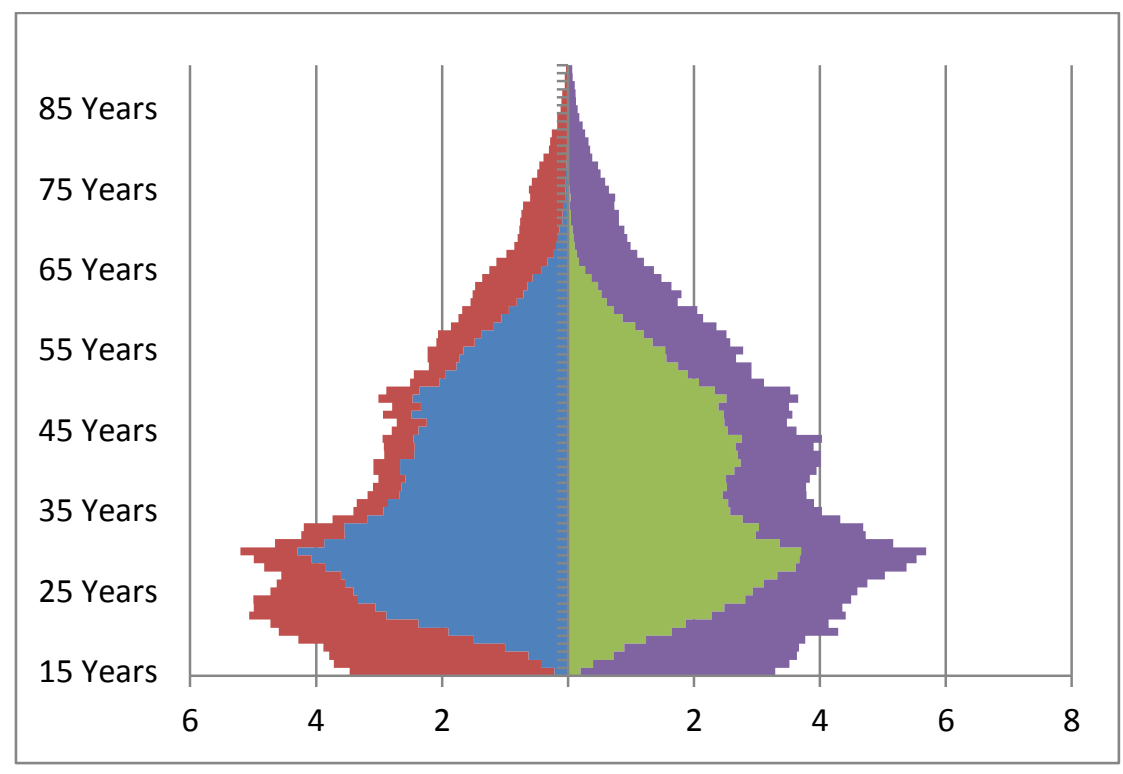

Among the Asian population more than MELAA, those who have a long period of settlement in New Zealand and those born in this country have significant levels of inter-ethnic partnering. For the majority of the recent migrants, the recent nature of their settlement means that inter-ethnic partnering, which predominantly occurs after arrival, is less extensive for the ethnic groupings as a whole. However, there is, for some groups, a high level of exogamy and again the populations are neither discrete nor independent.

Figure 11: Age-sex pyramid, work force, people of Middle Eastern, Latin American and/or African ethnicities, New Zealand census usually resident population, 2013 Censuses.

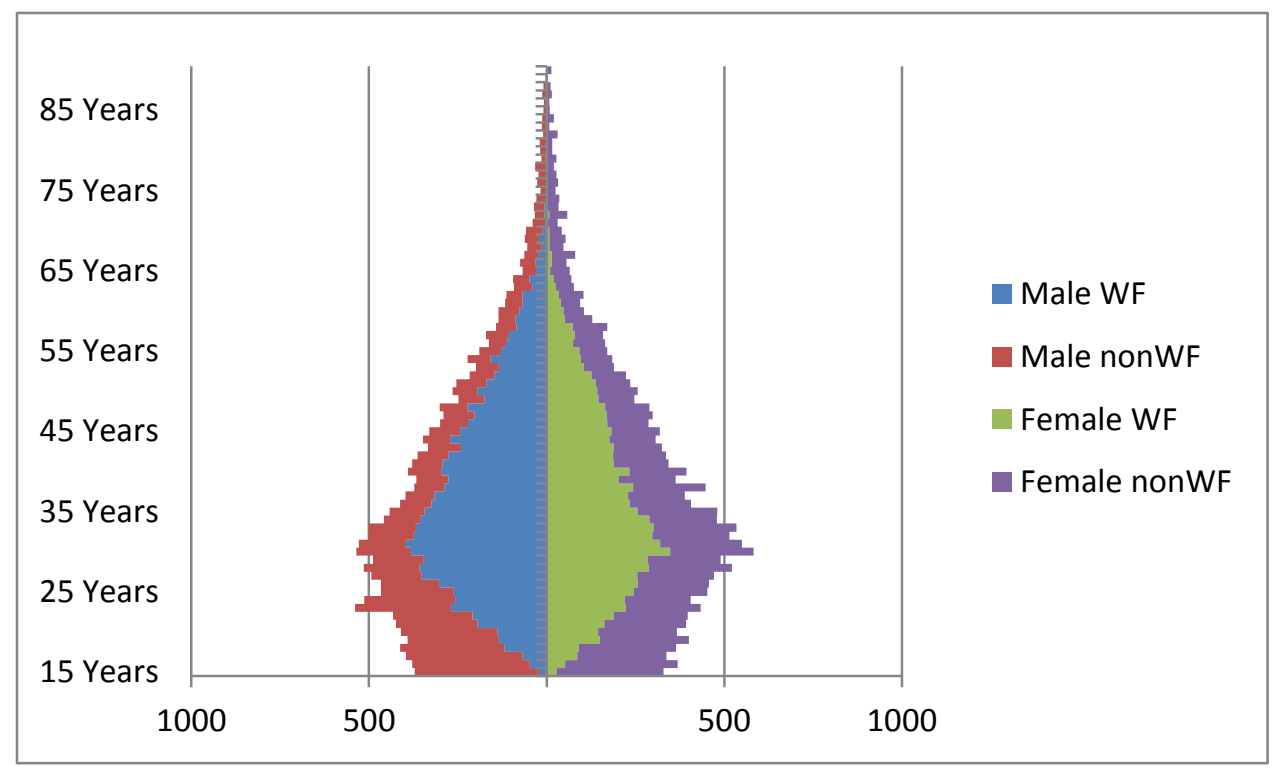

Some gender bias can be seen in the differences between those working or not working, and there is some gendered migration behind the patterns. Partly this is related to differences in the ways in which people have arrived, for example through skilled migration, family reunification or refugee 
flows, but we need also to remember that some people are, or have formerly been, international students who are resident in New Zealand for some years.

The striking feature for both the Asian and MELAA populations is the extent to which the size of the working populations don't peak until around 30 years. This is about 10 years older than for Pacific and Māori, in part that as a consequence of the different profiles. While the majority of Pacific and Māori in these age groups are New Zealand born, relatively few Asian and MELAA are.

\section{What are the young ones doing?}

We now look briefly at three stages of life histories with respect to work: the entry ages, the intermediate career paths and the exit ages.

Two views are shown here of the 10 cohorts who were in the 15-24 year age group in 2013. First we look at the transitions out of families and formation of their own new families, then we relate this to changes in labour market activity. These are shown by number of people, and cohort size varies slightly but this does not affect the picture in any material way.

Figure 12: Role in family, by sex, usually resident population aged 15-24 years, 2013 Census.

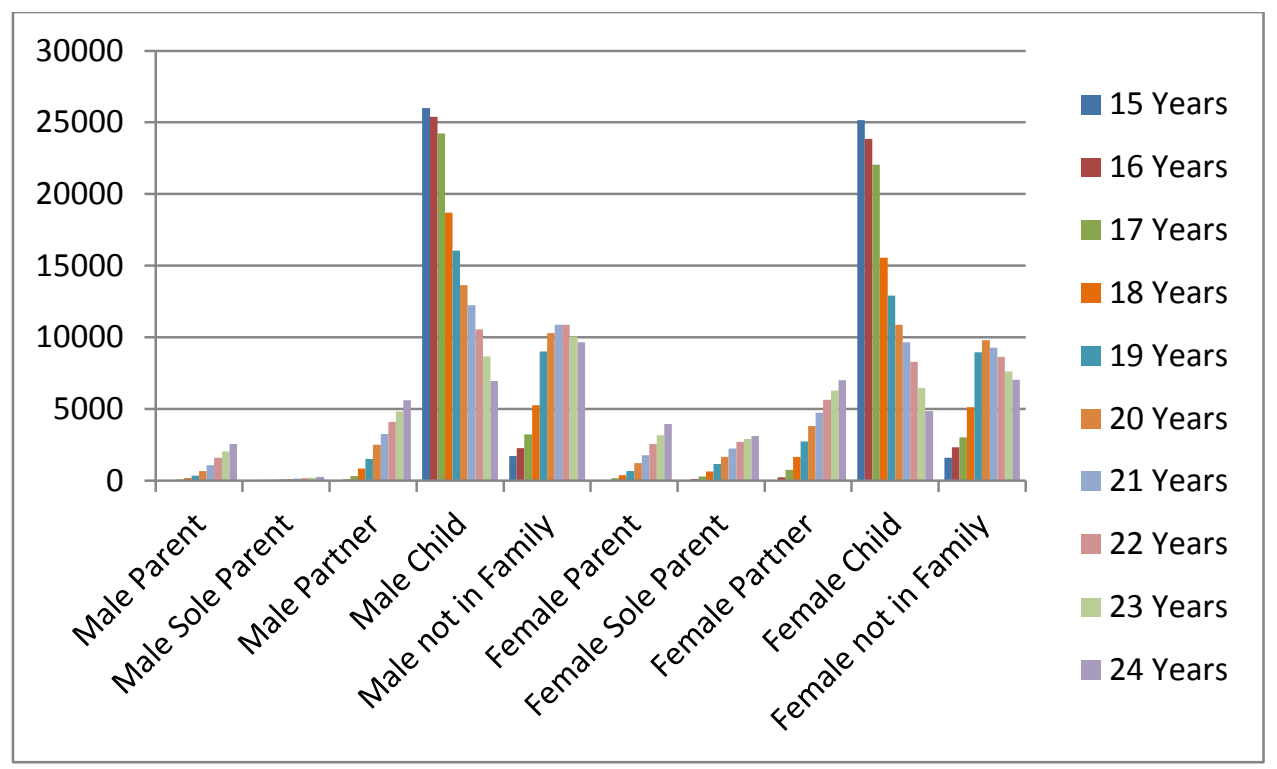

Figure 12 shows that the rate of drop off in numbers of those still at home with parents (i.e. they cease being a "child" in a family) is steep across 15 to 24 years of age - this is a transitional age group, with many people moving into adulthood and leaving home. The number who have left home but not yet in families rises sharply 15-20 then starts dropping off as people form their own new families, either as couples or as one parent families (the latter mostly females - with the number of male sole parents too small to register at the scale of this graph except age 24 years).

Figure 13: Labour force status, by sex, usually resident population aged 15-24 years, 2013 Census 


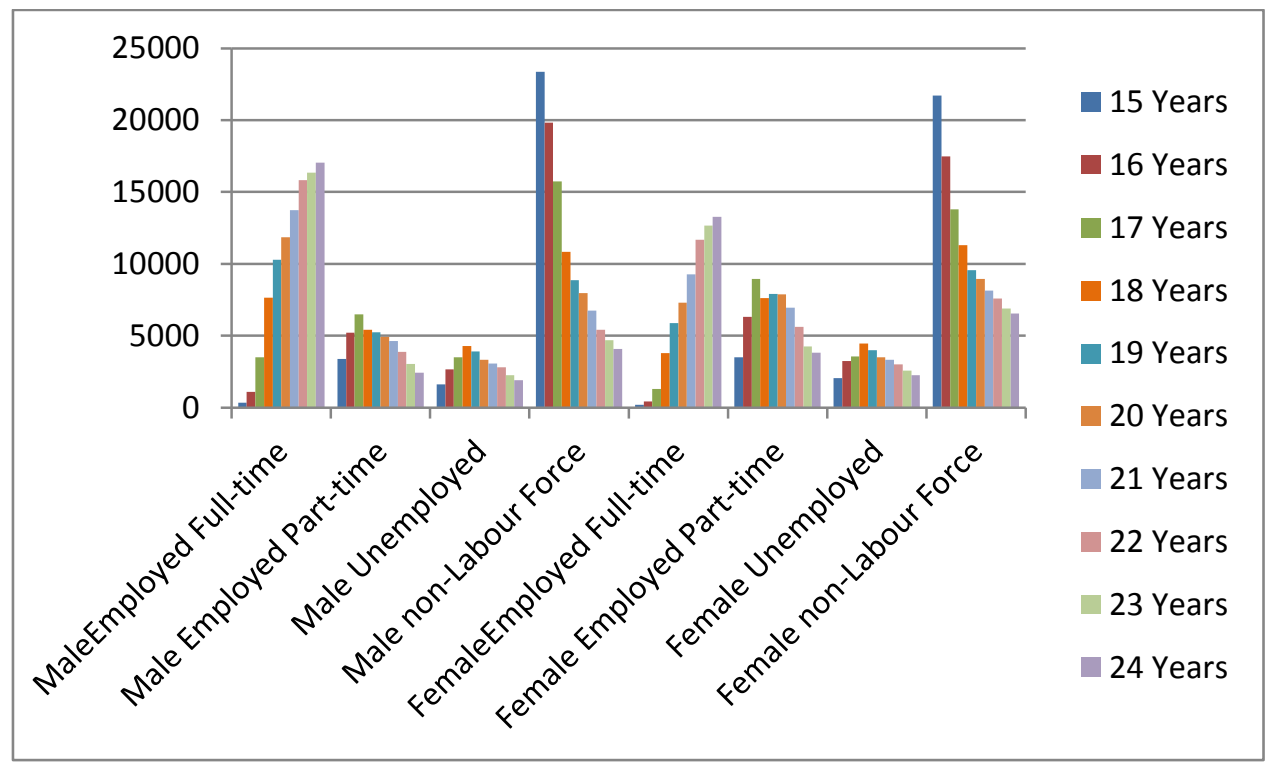

At the same time as these family transitions are occurring, we see (figure 13) a sharp shift for both males and females into labour force (with the majority of these moving into the work force, though unemployment is not insignificant). People who are studying are often outside the labour force. Women are more likely to stay outside the labour force than men, with much of this excess explained by the trends in one-parent family parents seen in figure 12 . However, many of both the males and the females in the non-labour force fall into the NEET category which is discussed elsewhere in these proceedings (Molloy and Potter, this volume).

People who continue with tertiary education, including trade training, frequently are employed, either through economic necessity or as a condition of their employment. Figure 14 shows the relationship between labour force status and participation in study. For simplicity, this is for total at each age for the 15-24 year age group: the patterns are almost identical for males and females. There are differences by sex, but these differences lie in what is being studied and at what level. The drop-off in the numbers studying and not working are similar to the increase in numbers who are working full-time and studying for the 17 to 20 year olds. Many of these are trade certificate students, of course. For those aged 20-24 both students in full-time work and students not working continue to decline, with only a small increase in those working part-time. This implies that there is a rapid disengagement with education, relatively low numbers in advanced education and skill acquisition. It is also probable that on-the-job training is not reflected in these data.

Figure 14: Labour force status and participation in study, usually resident population aged 15-24 years, 2013 Census 


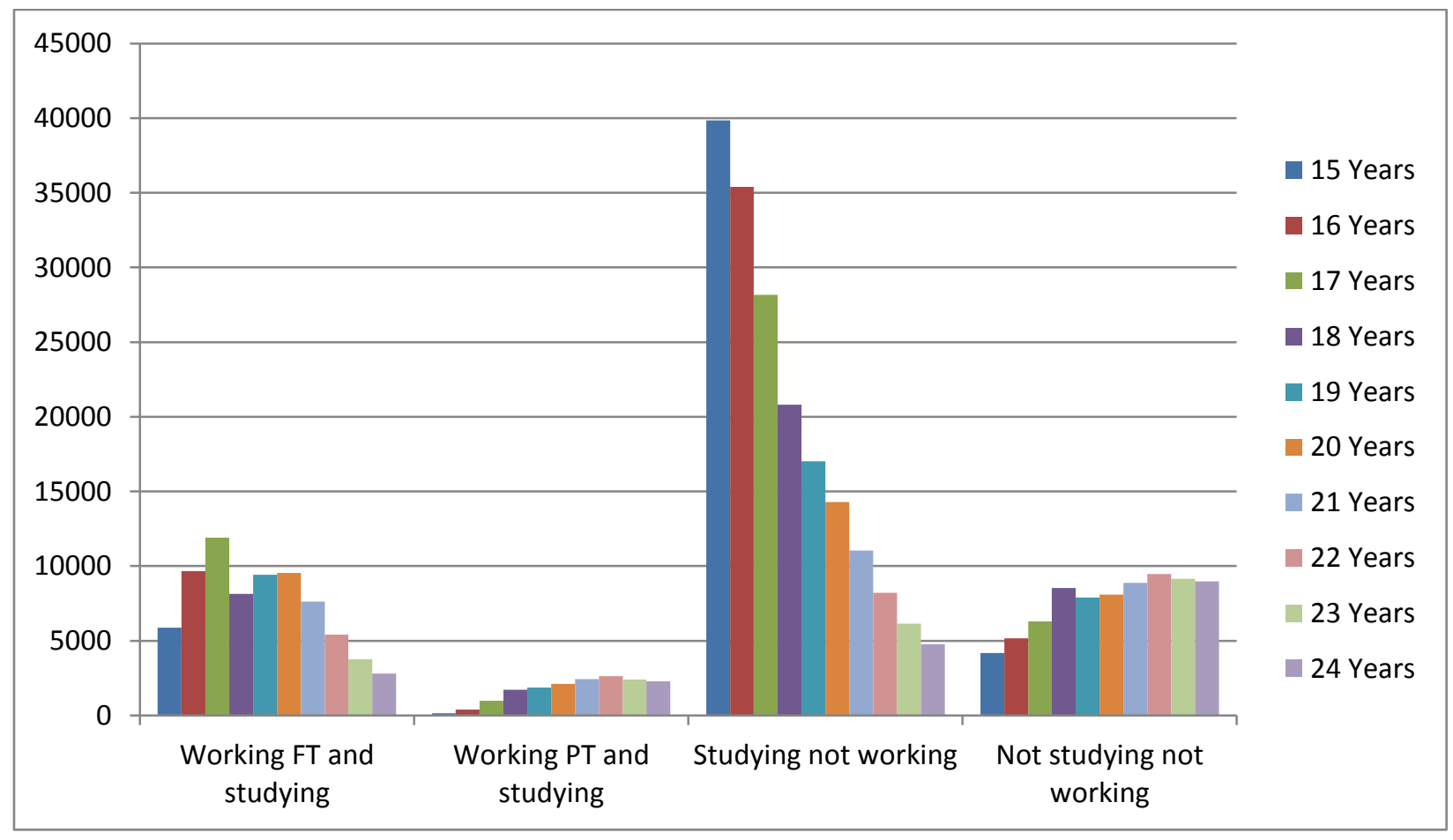

\section{Migrants and occupation}

As previously noted, the boundaries around the work force and the usually resident population are a little porous. We consider here are those people working in NZ and usually resident in NZ. This does include those working in New Zealand for more than 12 months, including some involved in the ChCh rebuild and other specific industries - generally these are few in number but they are locally important (in both the geographic and skill shortage senses).

Acquisition of skills and meeting the labour market demand for skills has been a major topic in economic development programs for over a century in New Zealand. Many skill requirements cannot be met by the available local infrastructure, and this is an increasing feature of the labour market despite some very strong advocacy among trade and academic education providers. People with locally acquired skills also move off-shore for periods of their lives and for a variety of reasons. Similarly people with high levels of skill, or who want to acquire skills within New Zealand, are available and willing to migrate to this country. Hence, migrants remain a vital part of the demographic picture. Figure 15 (males) and 16 (females) show the number of people born overseas working in New Zealand full time in each of the main occupation groups. These are not distinguished by years of residence in New Zealand and cannot be distinguished by migration pathway. Therefore they include people who may have migrated as children, or recently arrived, and may have come under family re-unification, for example, or through various skill-migration streams.

The number of men who are either managers or professionals reflects both the emphasis on skills in migration entry criteria and that when couples migrate together the male (assuming for this purpose that the partner is female) is usually the principal applicants. We also observe that the numbers are much higher in the mid-career ages, reflecting bother the time it takes to acquire the 
skills and that migrants in older ages are less likely to have high skills and there are fewer people in those occupation groups at those ages overall. Trade occupations are also predominantly male but this applies to both the overseas born and the locally born.

Figure 15: Occupation group (NZSCO), males born overseas employed full-time, usually resident population, 2013 Census

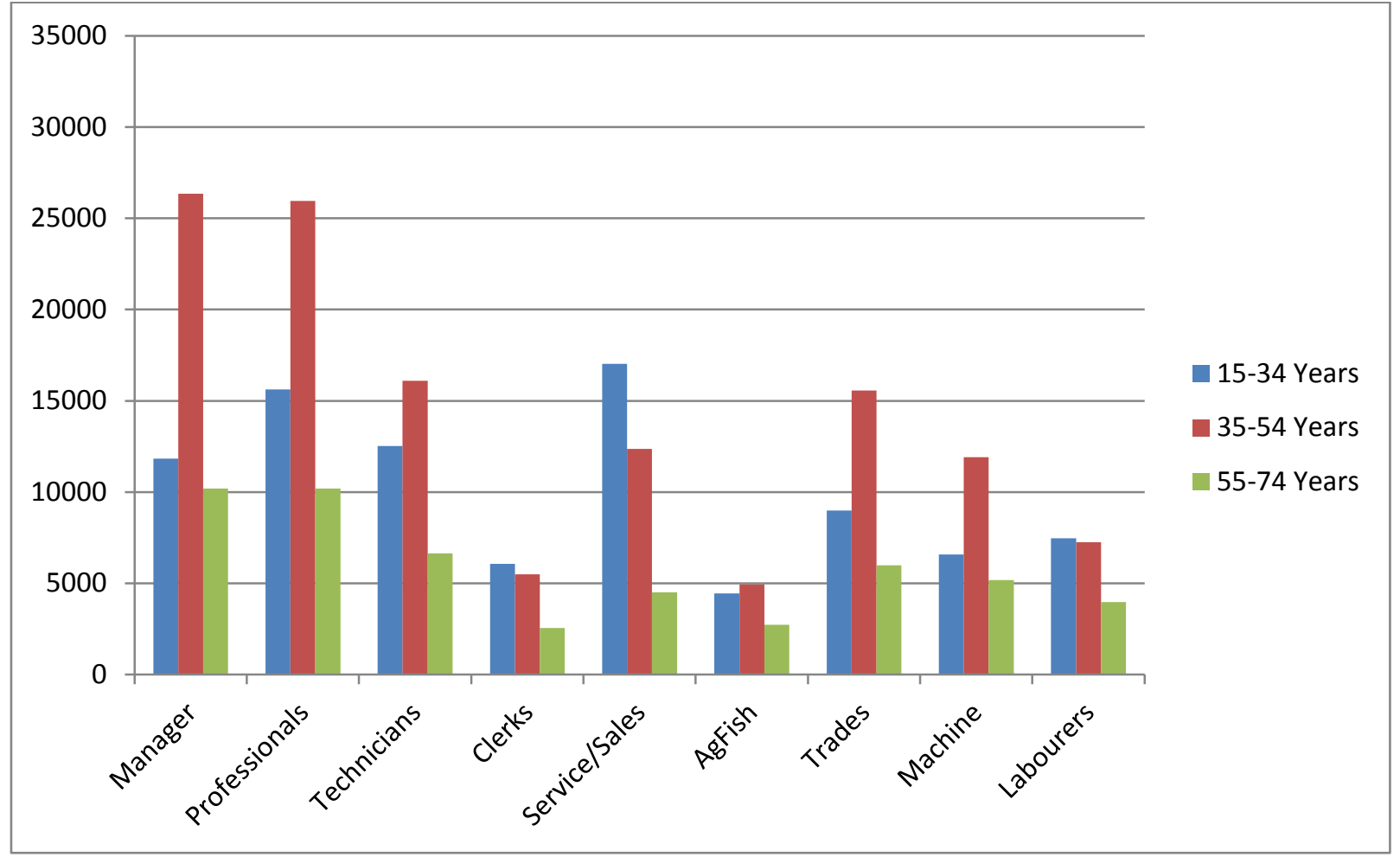

The pattern for women differs from men. Part of the explanation is related to migration pathways discussed in the previous paragraph, but a more cogent reason is the different distribution of skills. Of particular note is the number of mid-career women among the professionals. The majority of these are in health and education, the two occupation areas with increasingly lower proportions of male workers.

Figure 16: Occupation group (NZSCO), females born overseas employed full-time, usually resident population, 2013 Census 


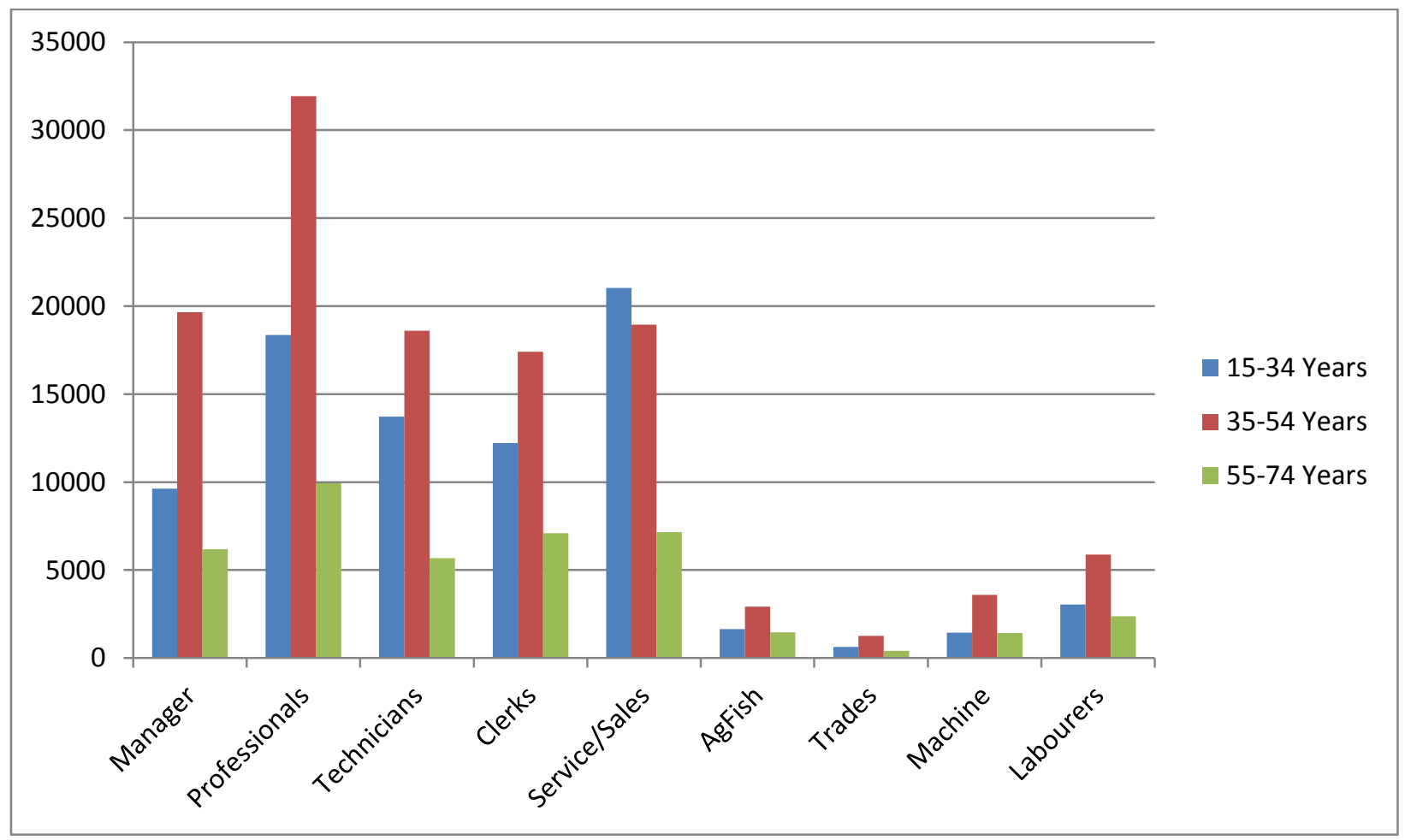

Because the occupation groups vary in size, it is difficult to get a good picture of some of the topics of interest. One such topic (for example in the care industry) is dependence on migrants in the work force. A simple way of illustrating this is to show the data in figures 15 and 16 as percentages of the whole occupation group (figures 17 and 18)

Figure 17: Percentage of occupation group (NZSCO) born overseas employed full-time, males, usually resident population, 2013 Census 


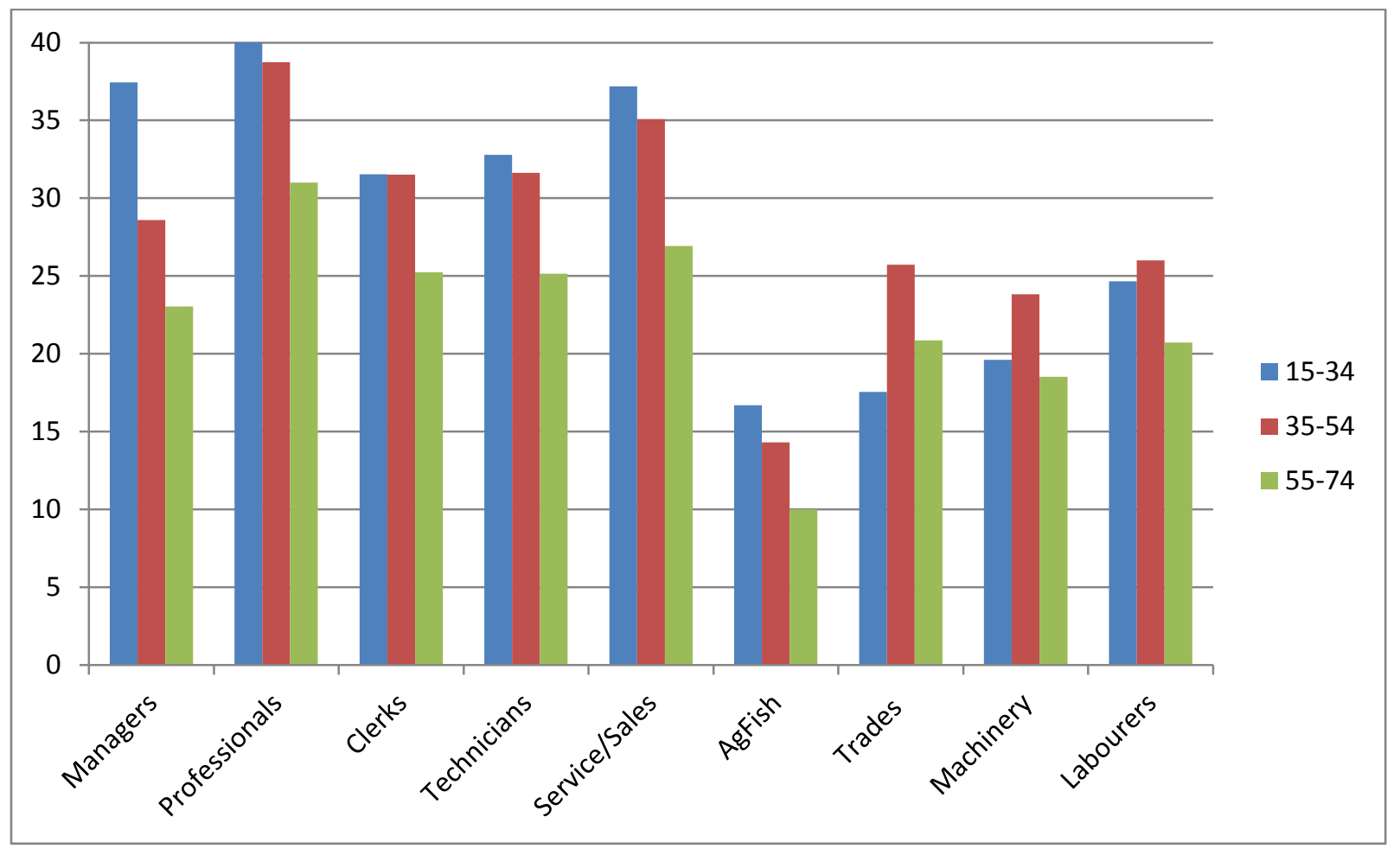

The substantial dependence on overseas born among professions partly reflects the impact of immigration policies over time. However both among the youngest age groups ( 40 percent) and the mid-career ages (39 percent) approaching half of professionals are overseas born. To get a full picture we would need to examine the data more closely by geographic origins, qualifications and length of residence in NZ. For example, in both Professionals and Managers groups, people born in the Pacific [approx. 1,000], Europe [4,000 including UK], Middle East [2,000]are all significant sources, but those born in Asian countries [7,000] slightly outnumber the combined total and also tend to be better qualified. Figure 17 shows that while the occupation groups to the right (except for agriculture) have only slightly more overseas born than the population as a whole, the data shows much higher concentration in the occupation groups to the left.

Females make up a lower proportion than men of the occupation groups in generally. However the group size differences is important. Mid-career overseas-born women outnumber overseas-born men by 23 percent among professionals (compare figures 15 and 16), and this is largely the result of very strong gendering in the health and education areas but make up less than $35 \%$ of the group compared with 40 percent for men. This suggests that gendering among the locally born is even stronger in these areas and reflects a major shift is gender balances among major professional occupations.

We also see a difference in the less skilled areas with much higher proportions of the workers born overseas. The concentration in the less skilled areas for women often conceals the fact that many are partners of male professionals. What is often overlooked in discussions about migration is that not all overseas born are highly skilled but are vitally important to areas of the labour market that still struggle to fill their labour requirements. It is noted that overseas-born women are in general 
more likely to be working full-time than locally born women, which will push the percentages here up, but the differences in distribution suggest that there is potential for further research in gender dynamics in relation to migration pathways.

Figure 18: Percentage of occupation group (NZSCO) born overseas employed full-time, females, usually resident population, 2013 Census

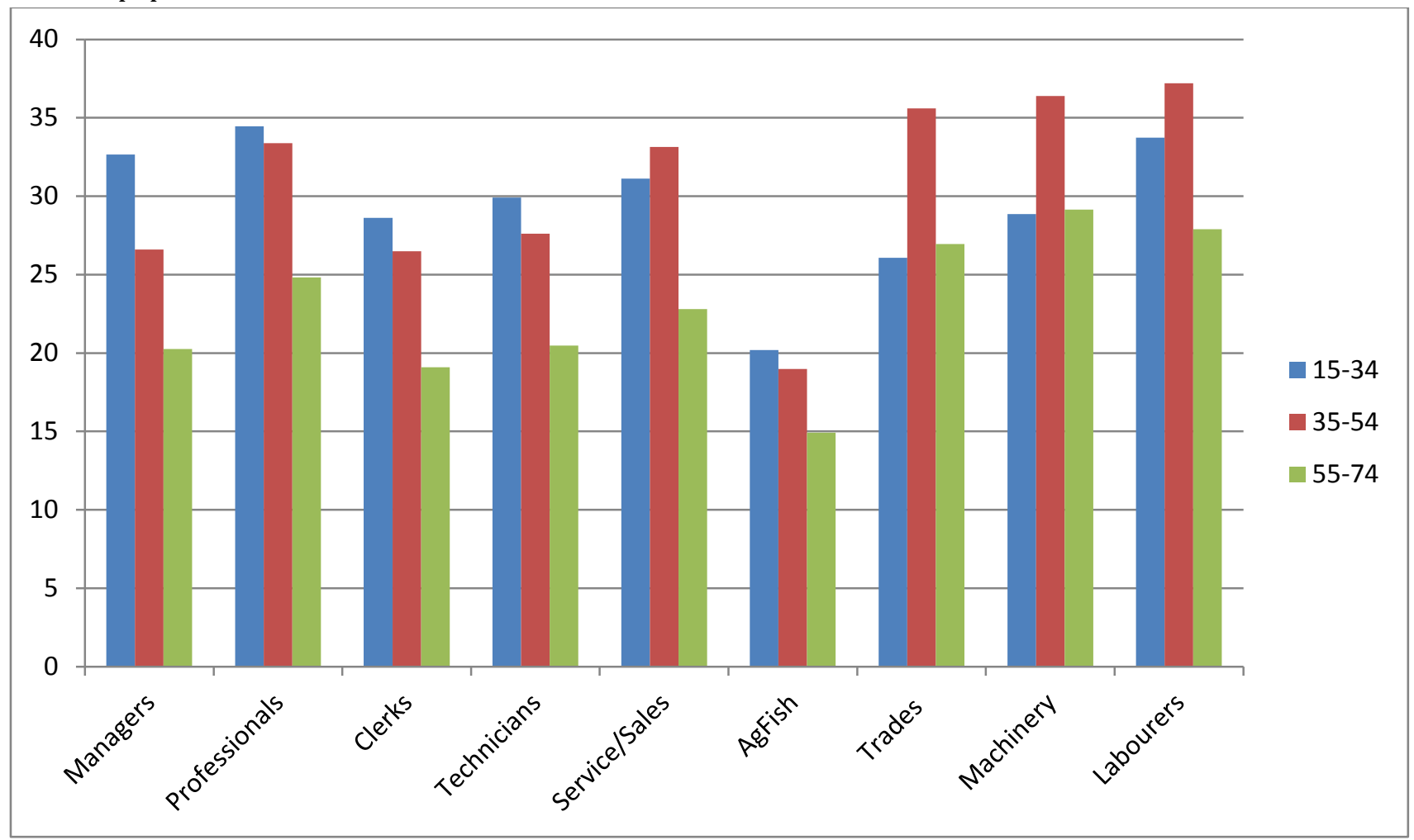

\section{Work force and the older ages}

We have looked above at labour market entry and at the migration element. Of equal importance is the processes and changes taking place at the exit end of working life. This is not just significant - it is increasingly significant. There is a very rapid growth in the number of people working in the older ages and this is a major component of the economic implications of population aging.

Men still substantially outnumber women in the full-time work force in these ages, but women slightly outnumber men in the part-time work force in the 65-69 year age group and look likely to overtake men in the older ages as well soon. However, there are many more women in these age groups so the participation rates are still lower. There are also clear differences in occupation distributions between men and women and between full-time and part-time work.

Figure 19: Older work force changes 1986-2013, full-time/part-time employed, by sex and age, 1986-2013 censuses (000's of people) 


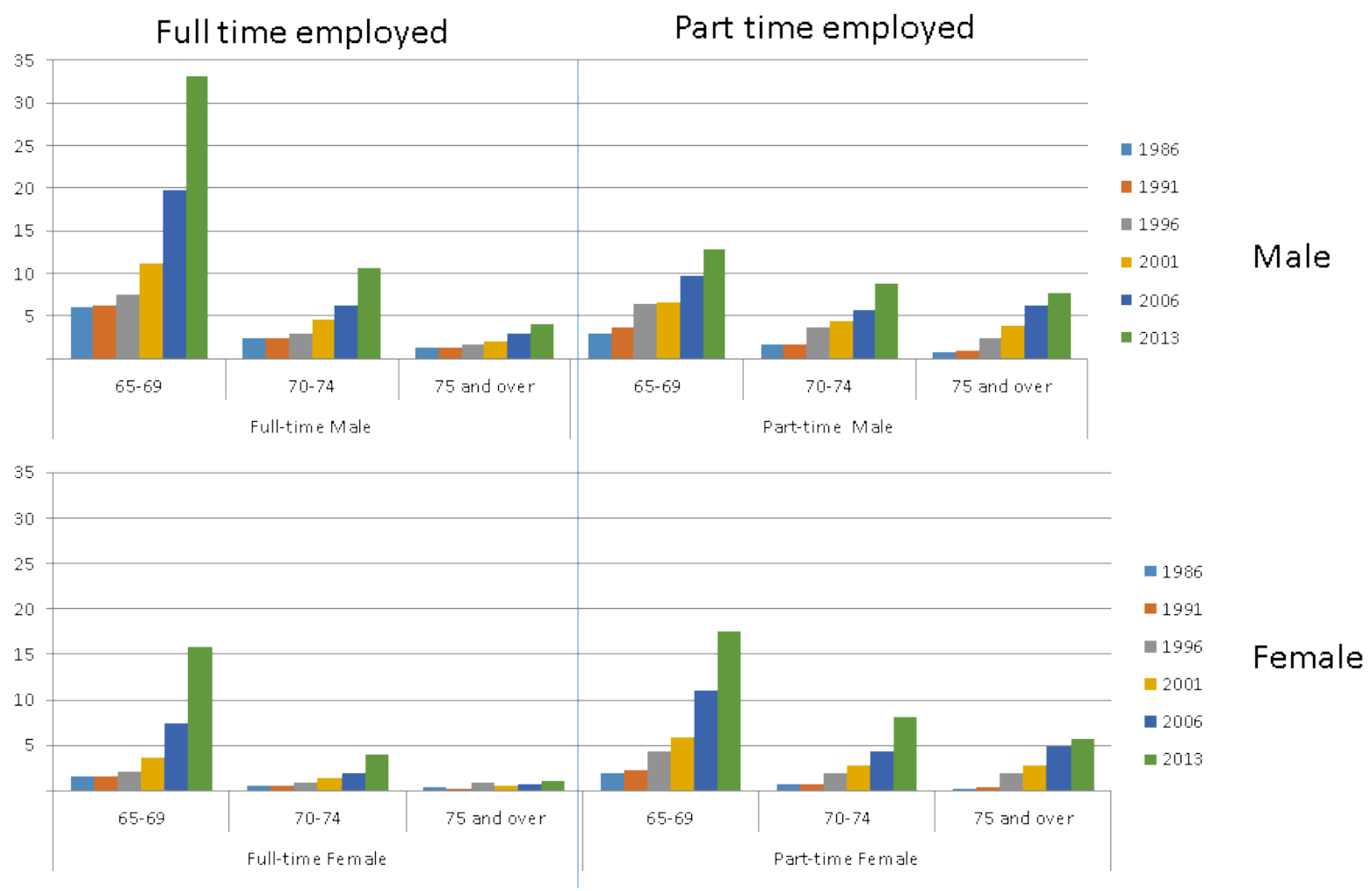

Occupations of the $65-69$ age group

Figure 19 looks slightly more closely at the 65-69 year age groups, since they represent the largest portion of those employed beyond the age of 65 years. Males only slightly more likely than females to be managers, but females more likely to be in the professions or clerical jobs if working full-time, but more likely to be clerical or sales/service (this is where the carers are) if they are working parttime. Women make up a major component of the part-time work force in some occupations: there are NUMERICALLY 40 percent more women than men working part-time in this age group.

A concern is that there are two clear trends when we look under these data. Firstly, highly qualified and skilled people are able to continue in professional roles if they have the ability and facilities to maintain skills and capability, but for people without this skill and resource base, the options are highly gendered - women into care-giving (an area of serious and growing labour shortage) and clerical type of occupations, whereas men dominate the industrial and labouring jobs (remember that few women at any age are yet in trades and men at all ages are under-represented in care industries and teaching)

Figure 19: Percentage distribution across occupation groups, full-time/part-time employed, by sex, 65-69 year age group, 2013 census 


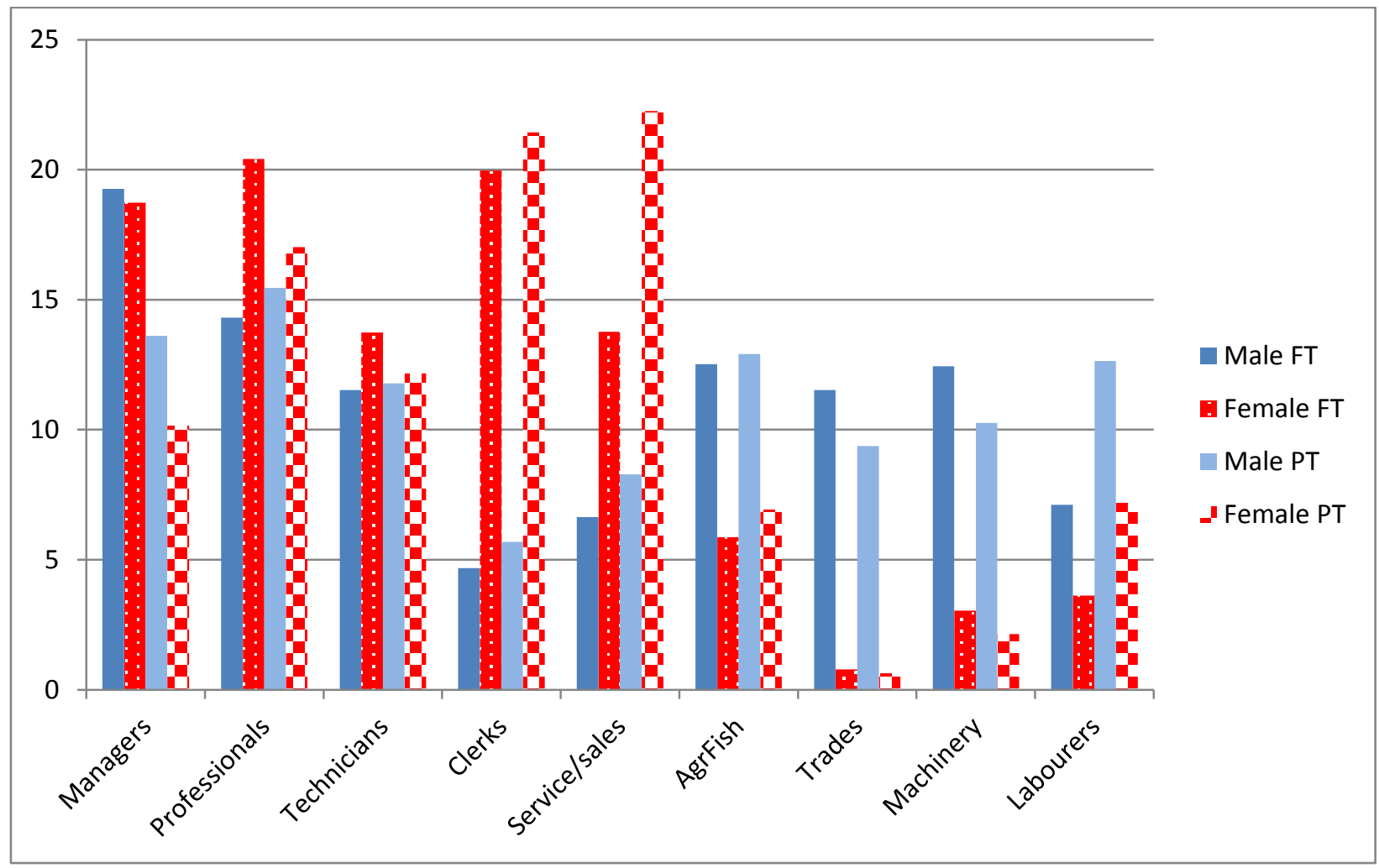

Males and females working in the older age groups

The number of male working beyond 65 years drops off very rapidly (figure 20) and those working tend to be either in the management/professionals categories or in trades, machine operators and labourers. But by far the greatest retention in is agriculture partly at least because the farm is also the family home this represents a slightly ambiguous situation and an opportunity that urbanbased people do not generally have. But the significance of agricultural work with respect to age of the work force is even greater when we remember that only about 12 percent of the 75 years and over males are rural, of whom 25 percent are working - but of these 75 percent are working in agriculture.

Figure 20: Occupation among older age groups, number of people (000's) and percentage distributions across occupation groups, male, 2013 census 


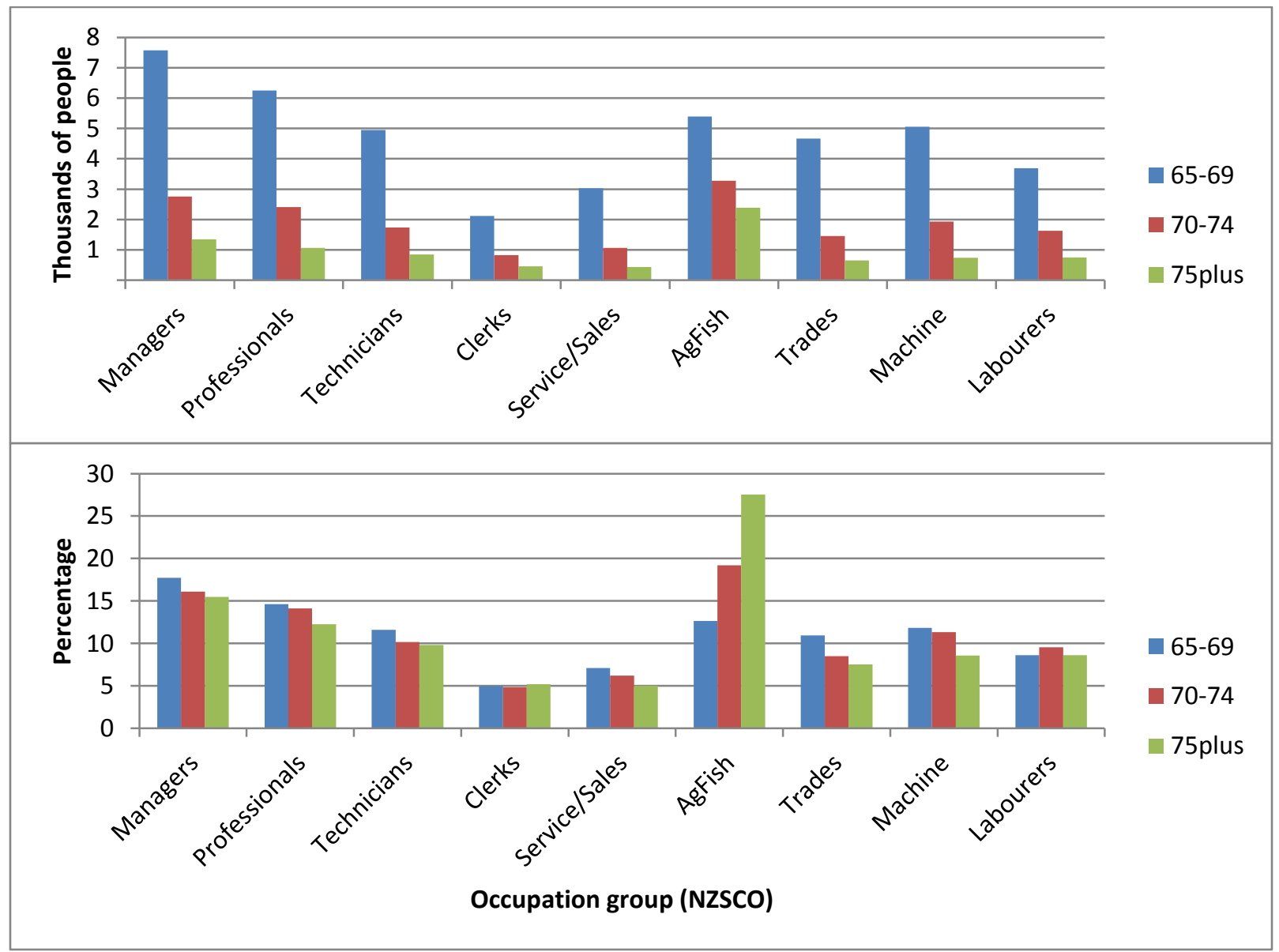

Female reveal a very different distribution (figure 21). As in other ages, very few are working in trades or as machinery operators. The drop-off rate differs too. There are nearly as many female as male professionals but the drop off is faster than for males. Among females, clerical and care workers represent a very important resource. As with males the percentage distribution by age rises with age for agriculture showing the same high levels of retention of older workers in that occupation group.

Figure 21: Occupation among older age groups, number of people (000's) and percentage distributions across occupation groups, male, 2013 census

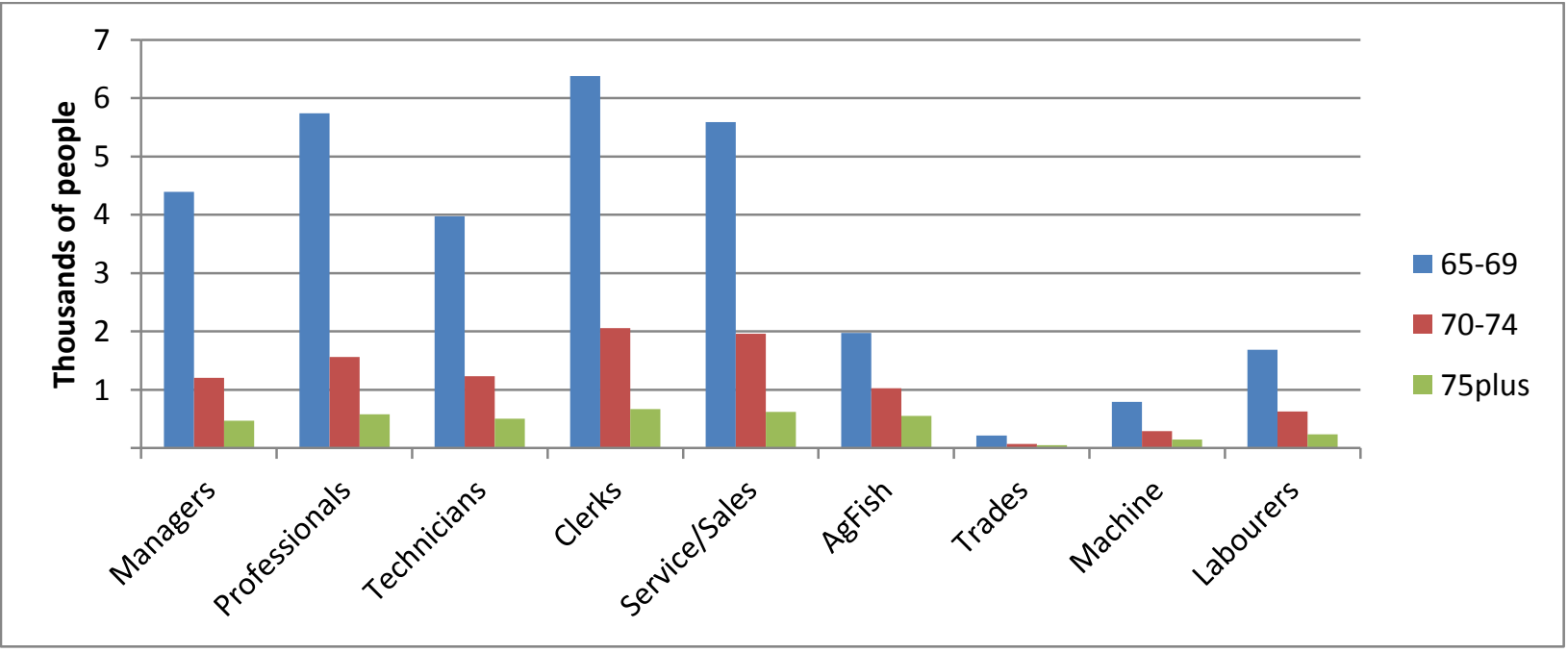




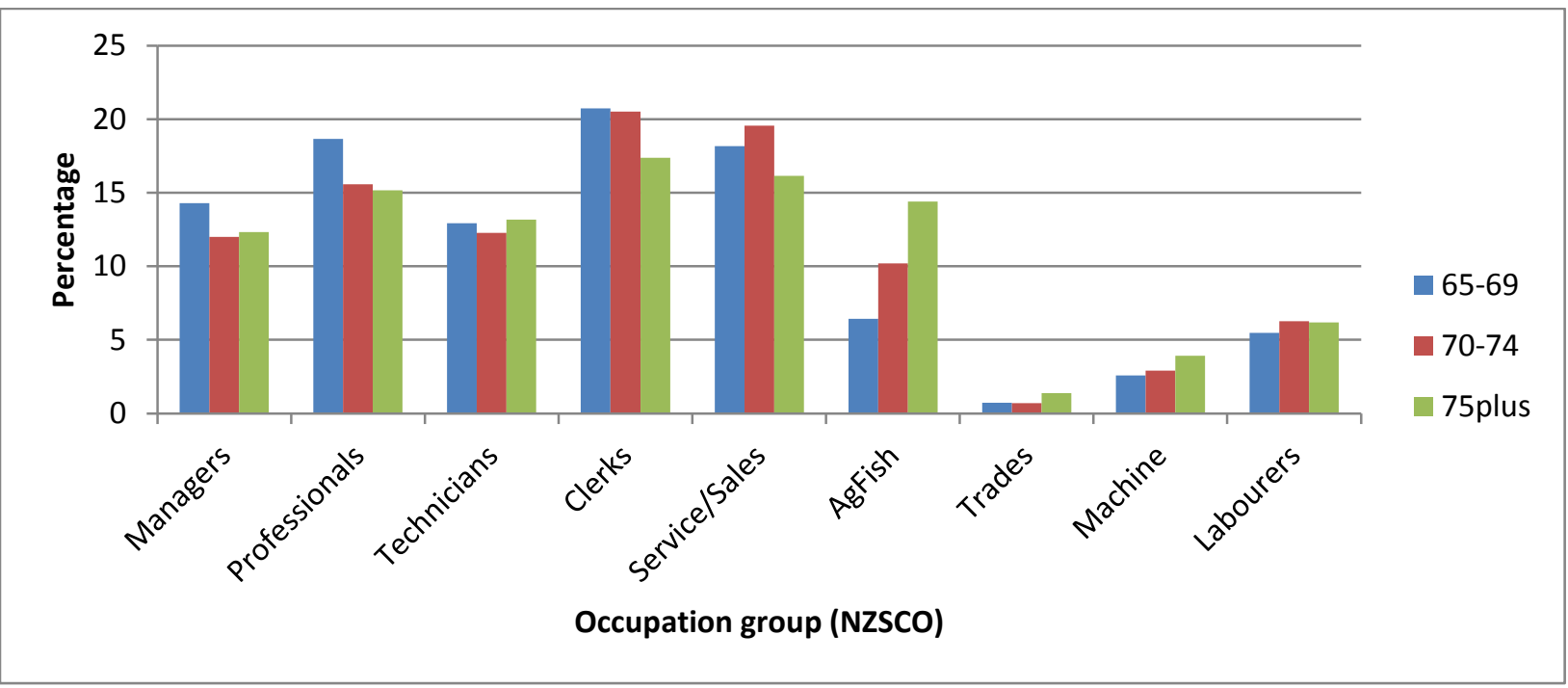

\section{Dependency and ageing}

One of the implications of changing demography and employment patterns is that the traditional simplistic dependency measure no longer have complete relevance.

The total dependency ratio refers to the ratio of the population under 15 years or 65 years and older as a fraction of the population aged 15-64 years. This is a crude measure because it assumes that the intervening ages are economically active and independent. But it is also a crude measure because the costs involved in supporting the two components are not symmetrical and these costs may be offset by the proportion of the numerator populations (whether working children or working elderly) who are economically active. As shown above, an increasing proportion of those aged 65 years and over are working. Other may not be employed but may be independent economically.

Child dependency is the ratio of the population under 15 to those aged 15-64 years. However, some under 15 years are economically active, while many aged 15-24 are not. However, these patterns are continually changing so measuring across time can be misleading. Key question that would warrant further consideration include whether people currently economically inactive will remain so, whether the age of entry to work force will rise over time and whether credentialism and qualification inflation will continue to change the playing field, and if so how? These aspects affect measures of the labour force and the work force.

Aged dependency is usually based on those 65 years and over. However, changes in work patterns outlined above and health (especially physical and mental in the oldest ages) affect real burden of care. Provision of this care is an area of substantial policy interest.

Figure 22 shows the changes in the age structure for New Zealand from 1901 and projected to 2051. While this shows clearly the changes in the sex ratios, for example the relationship between the males 65 years and over versus the females 65 years and over, it also incidentally has 
highlighted a major feature: same proportion of males were under 40 in 1901 as there will females under 65 in 2051.

In terms of economic implications, the critical bands are the 15-39/40-64 - most employed people are currently in these ages and if the bands get narrower over time, the age dependency ratios increase. Child dependency and aged dependency have different costs and different implications. The very interesting aspect of this graph is that it contains two periods with high levels of interest in migration, diasporas and aging - around 1921 and the last decade - just to cite some examples: both periods were preoccupied with similar concerns: high levels of exchange of people (e.g. a lot more Australians in New Zealand than New Zealanders in Australia in the early period, the opposite of what we have now), loss of New Zealanders across the world, falling fertility, and concern over pension affordability.

Figure 22: Age composition by key age groups, males and females, New Zealand population 1901-2051

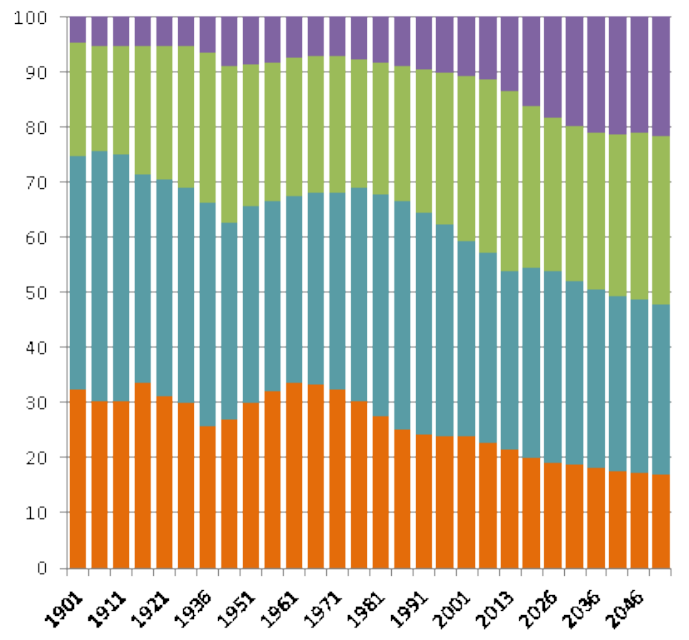

Males

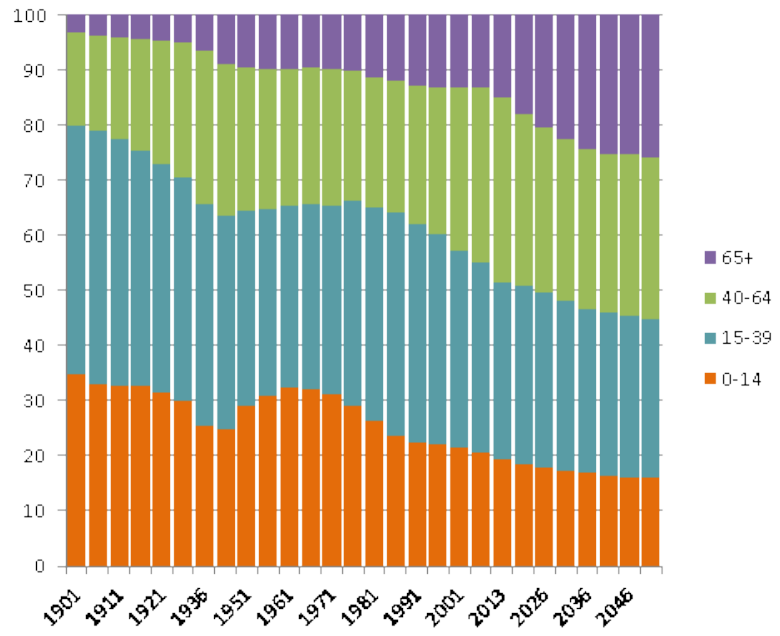

Females

Of current concern is the retention and maintenance of highly trained skilled specialist labour - an example is in the aged care industry which is heavily reliant on migrant labour for a number of reasons - increasingly this sector of health and care provision is dependent on countries like the Philippines and India - the risk is that reliance on migrant labour will discourage local investment in the skill base and erosion of working conditions since it is always easier to exploit migrant labour. Health and disability care is the obvious area with skill shortages, but NZ also increasingly short of skills across a number of other areas (science in general, social sciences in particular). One should also remember that low-skill jobs need to be filled, respected and equitable.

Of central concern to most discussions is the effects of population ageing. This extends far beyond work force requirements to service emerging needs, of course. Total dependency rates are projected to fluctuate but increase of less than 5 percentage points, as figure 23 shows. The major change is the ratio of youth dependency to aged dependency. This is important because the relative 
cost and resource requirements differ for each group, but more important for assessing impact is that the rate of change varies sharply. Sex ratios also differ, with females significantly more numerous than males in older ages, and males slightly more numerous among children. However to make real sense of these, and a potential topic of more research, we need much more information e.g. what will be the norm for school leaving age and entry into employment for males and females? What will happen to fertility and childbearing norms? What proportion of the population (both males and females) will be employed beyond the age of, say, 75 years?

Figure 23: Projected dependency ratio, male, female and total, New Zealand population 2024-2054

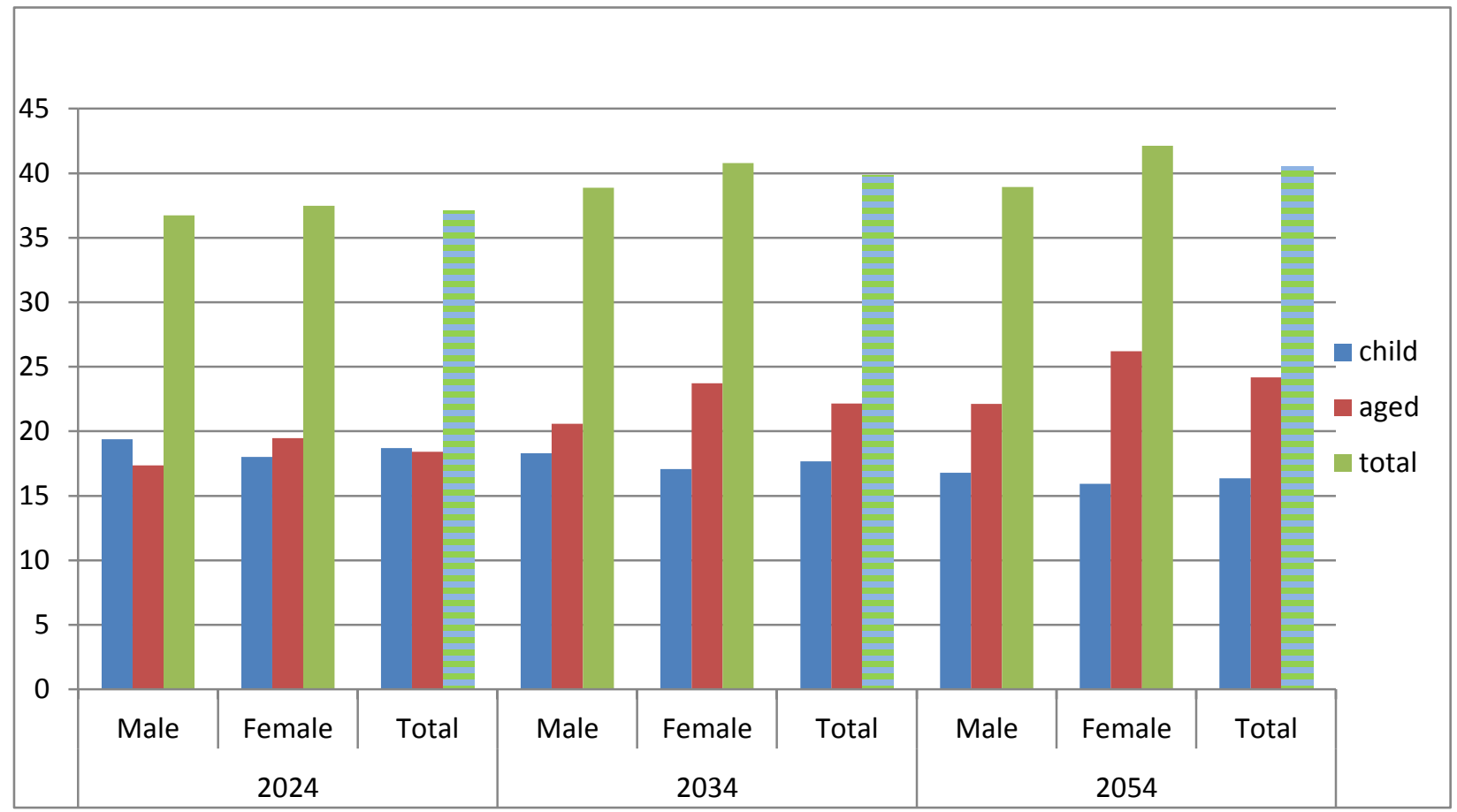

With ongoing continuation of increasing employment into the older ages, the gap between work and death might shrink rapidly, as will availability of people to undertake much of the unpaid work currently performed by older people. The shrinking gap between retirement and death is a very important consideration for populations (such as Māori) with lower life expectancies, if their expectations of longevity of employment increase. Already in Australia questions are being posed such as "will the Aboriginal populations ever be able to retire?" This raises a serious issue of equity with major policy implications. 